\title{
EFICÁCIA DO LASER DE BAIXA INTENSIDADE NA ACELERAÇÃO DO MOVIMENTO ORTODÔNTICO
}

\author{
BÁRBARA APARECIDA MARQUES SUMMA .
}

1 Graduada pela Faculdade de Odontologia da UERJ, Especialista em Ortodontia pela FACSETE.

\section{RESUMO}

A terapia à laser de baixa intensidade (TLBI) fornece vários benefícios para os pacientes que recebem o tratamento ortodôntico. O movimento do tratamento rtodôntico (MTO) pode ser melhorado, mas alguns relataram resultados contraditórios. Neste artigo, foi realizada uma revisão da literatura sobre os diferentes aspectos do uso da TLBI no MTO e suas alterações. Alguns trabalhos verificaram que a quantidade de movimento dos dentes no grupo irradiado com laser foi significantemente maior do que no grupo não irradiado. A irradiação com laser de baixa potência acelera o processo de remodelação óssea, estimulando a proliferação de células osteoblásticas e osteoclásticas e função durante a movimentação ortodôntica. Alguns artigos relataram que o uso do LBI, além de acelerar o movimento ortodôntico, pode contribuir para modular a dor. A laserterapia na Odontologia se tornou uma técnica promissora, eficiente e de baixo custo para o paciente. Por esse motivo, este trabalho visa revisar a literatura a respeito da eficácia do LBI na movimentação ortodôntica.

Palavras-chave: Laser de Baixa Intensidade; Aceleração do Movimento Ortodôntico.

\section{EFFICACY OF LOW INTENSITY LASER IN THE ACCELERATION OF ORTHODONTIC MOVEMENT}

\begin{abstract}
Low level laser therapy (LLLT) provides multiple benefits for patients receiving orthodontic treatment. According to some literature, the orthodontic treatment movement (OTM) can be improved, but some have reported contradictory results. This paper made a review of the literature on different aspects of LLLT use in MTO and its amendments. Some studies have found that the amount of movement of the teeth in the group irradiated with laser was significantly higher than in the non-irradiated group. Irradiation with low power laser accelerates bone remodeling process, stimulating the proliferation of osteoblastic and osteoclastic cells and function during the orthodontic movement. Some articles reported that the use of LLLT and accelerate orthodontic movement, can contribute to modulate pain. Laser therapy in dentistry has become a promising technique, efficient and low cost to the patient. Therefore this work aims to review the literature regarding the efficacy of LLLT in orthodontic tooth movement.
\end{abstract}


Keywords: Low-level laser therapy; Orthodontic tooth movement acceleration.

\section{INTRODUÇÃO}

O uso do laser de baixa intensidade na Odontologia tem aumentado na última década, com estudos que publicam a sua eficácia no tratamento ortodôntico. O LBI demonstrou-se uma modalidade de tratamento não invasivo para acelerar o movimento e reduzir a dor e isto gera um benefício mútuo para pacientes e profissionais.

O tratamento ortodôntico, com base no movimento dentário, é um processo demorado, com duração média de tratamento entre 2 a 3 anos. Este longo prazo geralmente resulta na diminuição da adesão de pacientes,e também é capaz de causar uma variedade de efeitos colaterais, tais como a reabsorção óssea alveolar, reabsorção radicular, cáries, por conseguinte, o encurtamento do tempo de tratamento ortodôntico é desejado (LONG et al., 2013).

Muitos estudos têm pesquisado diferentes métodos para acelerar a movimentação dentária, incluindo injeções de drogas, estimulação elétrica, campos magnéticos pulsados e corticotomia. Embora alguns desses métodos sejam eficientes, eles podem causar alguma experiência desagradável em pacientes (GE et al., 2015). Por isso, pesquisas a procura de métodos minimamente invasivos que melhorem $o$ movimento ortodôntico com pouco efeito colateral e baixo custo se intensificaram e o LBI tem se mostrado muito eficazes (QAMRUDDIN et al., 2017).

Evidências científicas relatam que o tratamento a LBI, além de reduzir a dor, acelera o movimento a partir de um processo de remodelação óssea (proliferação de osteoblastos e osteoclastos) e síntese de colágeno (principal proteína da matriz óssea). (DE ALMEIDA et al., 2016).

O laser de baixa intensidade é considerado uma técnica mais promissora, devido ao seu efeito bioestimulante, forma não invasiva e de fácil acesso ( SUZUKI et al., 2018). Assim, o objetivo deste trabalho foi descrever, por meio de uma revisão bibliográfica, as evidências da eficácia do laser de baixa intensidade na aceleração do movimento ortodôntico.

\section{REVISÃO DE LITERATURA}

Cruz et al. (2004) realizaram um estudo para avaliar a influência da terapia laser de baixa intensidade (TLBI) na velocidade da movimentação ortodôntica na retração de caninos. Foram avaliados 11 pacientes com idade entre 12 e 18 anos, com indicação de extração dos primeiros pré-molares superiores. Cada paciente teve uma hemiarcada, sendo grupo controle (GC) e outra hemiarcada designada grupo laser (GL), aleatoriamente. Os 11 pacientes tiveram seus primeiros pré-molares extraídos. Os caninos foram alinhados e nivelados com aparelho fixo com prescrição Roth e com fios de Ni-Ti 0,12 ", 0,14 " e 0,16 " e fios de aço 0,18 " e 0,20 " redondos e 0,17 "x 0,25 " retangulares. Um arco de Nance modificado foi cimentado nos segundos pré-molares superiores e uma barra palatina foi cimentada nos primeiros molares superiores para ancoragem posterior. A retração canina foi feita através do uso de molas fechadas de NiTi e $150 \mathrm{~g}$ de força constante. Foi usado aparelho laser diodo emitindo radiação infravermelha contínua a $780 \mathrm{~nm}$, com potência de $20 \mathrm{~mW}$, dose de $5 \mathrm{~J} / \mathrm{cm}^{2}$ e 10 
segundos de exposição. A cada irradiação, 10 pontos foram irradiados, sendo em 5 vestibulares e 5 linguais. Este estudo mostrou que o GL obteve uma retração estatisticamente significativa, 34\% maior que o GC. A TLBI ocorreu nos dias 0, 3, 7, $14,30,33,37$ e 44 . Os resultados sugerem que a TLBI acelera significativamente movimentação ortodôntica de forma saudável.

Limpanichkul et al. (2006) realizaram um estudo com objetivo de testar a hipótese de que a terapia laser de baixa potência (TLBI) pode aumentar a taxa de retração ortodôntica de caninos superiores em comparação ao grupo placebo. Foram avaliados 12 pacientes adultos jovens (4 homens e 8 mulheres, com idade média de 20,11 anos) com os dois primeiros pré-molares superiores extraídos após completo alinhamento e nivelamento dental e a pelo menos 3 meses antes de começar a retrair os caninos. De forma aleatória, cada hemiarcada de cada paciente foi alocada no grupo controle (GC) ou no grupo laser (GL). Foi instalado aparelho fixo com prescrição Roth em todos os paciente e em todos os dentes, menos nos caninos a serem retraídos, nos quais foi usado braquetes autoligados. Foi usada uma mola helicoidal fechada de NiTi para distalizar os caninos (Figura 1), com força de $150 \mathrm{~g}$ entre o canino e o primeiro molar superiores. As molas foram reativadas uma vez por mês para reativar a tensão da mola a $150 \mathrm{~g}$. Um laser GaAlAs com potência de $100 \mathrm{~mW}, 0,09 \mathrm{~cm}^{2}$, densidade de potência de $1,11 \mathrm{~W} / \mathrm{cm}^{2}$, dose de energia de $2,3 \mathrm{~J}$ e densidade de energia de $25 \mathrm{~J} / \mathrm{cm}^{2}$. Foram irradiados 3 pontos vestibulares e 3 pontos palatinos na mucosa alveolar e 2 pontos na distal do canino, por 23 segundos por ponto. Após a aplicação do primeiro dia da TLBI, os pacientes foram convidados a retornar para aplicações repetidas nos próximos dois dias. Esta aplicação de TLBI de 3 dias foi então repetida no final do primeiro, segundo e terceiro mês. No início de cada um dos 4 conjuntos de TLBI, antes de colocar os arcos e reativar as molas, foi realizada moldagem do maxilar com alginato e confeccionado um molde. Nestes modelos de gesso, foram realizadas medições para controle das retrações (Figura 2). Como resultado, os autores não encontraram diferença estatística significativa na distalização dos caninos entre GL e GC. Os autores concluíram que a TLBI, nos parâmetros adotados neste estudo, não teve efeito sobre a taxa de movimentação ortodôntica em qualquer período de tempo. A densidade de energia usada neste, provavelmente, foi muito baixa para expressar qualquer efeito estimulador ou inibidor da taxa de movimento.

Figura 1: Modelo mola helicoidal fechada de NiTi para distalizar os caninos

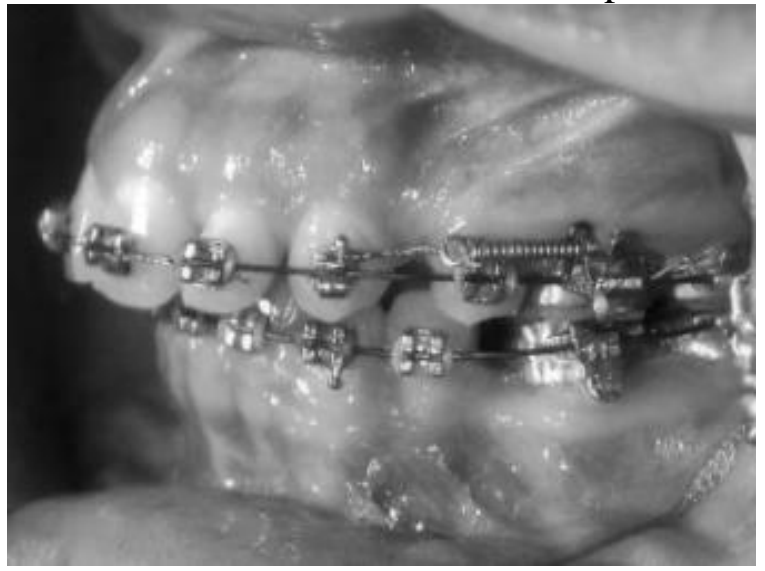

Fonte: Limpanichkul et al., 2006, p. 39 
Figura 2: Modelo de gesso para medição da quantidade de retração do canino

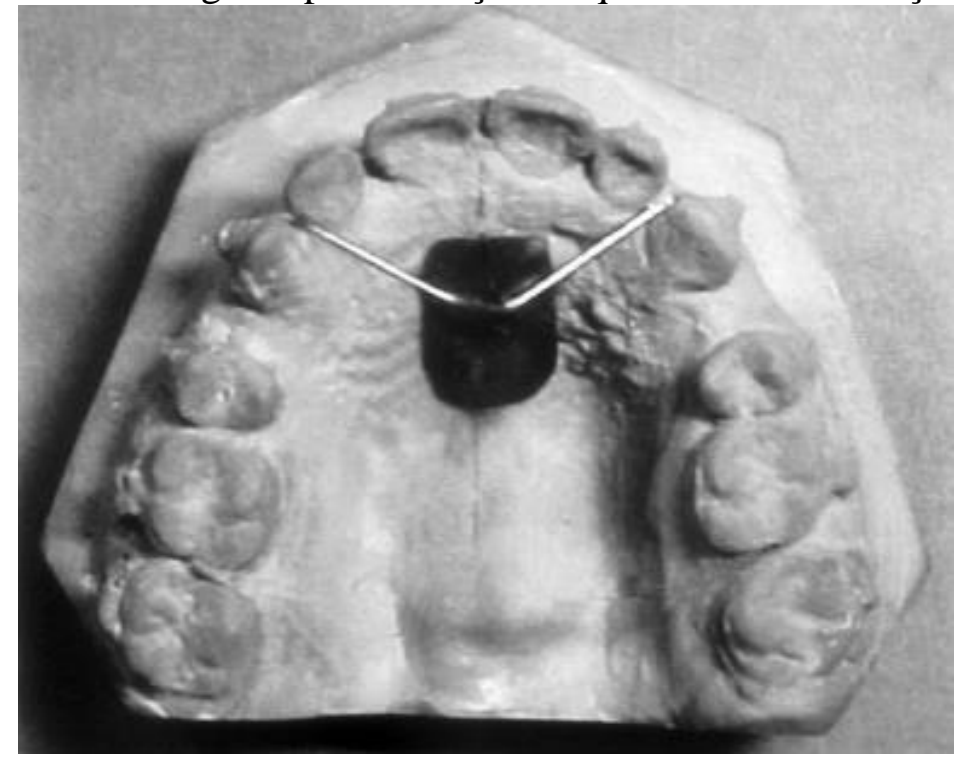

Fonte: Limpanichkul et al., 2006, p. 41

Seifi et al. (2007) realizaram um estudo para comparar a velocidade do movimento ortodôntico de dentes de coelhos submetidos a terapia laser de baixa potência (TLBP) de dois diferentes comprimentos de onda. Foram avaliados 18 coelhos, divididos em 3 grupos com mesmo número de indivíduos (6): Grupo Controle (GC), Grupo Laser 850nm (GL850), e Grupo Laser 630nm (GL630). Nos coelhos dos 3 grupos, foi instalado fios ortodônticos $1 / 100$ polegada e, nos primeiros molares, foi aplicada força para mesial através de mola helicoidal de NiTi fechada, com força de $100-120 \mathrm{~g} / \mathrm{cm}^{2}$. Os coelhos do GC não receberam TLBP. No GL850, por nove dias, foi aplicado laser de $850 \mathrm{~nm}$ com potência de $5 \mathrm{~mW}(3,000 \mathrm{~Hz})$, com total de energia de $8,1 \mathrm{~J}$ e no GL630, nos mesmos 9 dias, um pulso contínuo em $10 \mathrm{~mW}$, com energia total de 27J. Depois de 16 dias, no término dos tratamentos, a distância entre a distal do primeiro molar e a mesial do segundo molar foi medida e estatisticamente analisada. $\mathrm{O}$ estudo mostrou que o movimento dos dentes nos GL850 e GL630 foi estatisticamente menor que no GC; no entanto, a diferença entre os dois grupos laser não é estatisticamente significativa. Os autores concluem que a TLBP, da maneira como foi aplicada, diminuiu a velocidade de movimentação dentária, provavelmente pelo fato de a energia e dose aplicadas tenham sido demasiadamente alta para coelhos.

Youssef et al. (2008) fizeram um estudo com o objetivo de avaliar a terapia com laser de baixa potência em retrações de caninos durante o movimento ortodôntico e o nível de dor. Sua amostra consistia de 15 pacientes, idade entre 14 e 23 anos e que o plano de tratamento incluía extração dos primeiros pré-molares superiores e inferiores. O tratamento foi iniciado 14 dias após a extração e foi usado braquetes Edgewise slot 0,018 padrão. Para a retração, foi usada uma mola pré fabricada e fio 16"x16" Elgiloy Azul, com força de $150 \mathrm{~g}$, reativada a cada 21 dias e repetida até o fechamento do espaço da extração. A medição do espaço foi feita com paquímetro da ponta da cúspide mesial dos primeiros molares à extremidade da cúspide dos caninos, nos modelos de estudos feitos nas datas de reativação. E a cada reativação, o paciente era questionado sobre a dor experimentada no período passado. O laser utilizado foi um semicondutor (GaAlAs) com $809 \mathrm{~nm}$ de comprimento de onda, saída de $100 \mathrm{~mW}$, irradiando a lingual e vestibular dos caninos, nos terços cervical (10 segundos), médio (20 segundos) e apical (10 
segundos), sendo assim uma densidade total de energia de $8 \mathrm{~J}$ por aplicação. O laser foi aplicado em intervalos de 0, 3, 7 e 14 dias após cada ativação. Em cada intervalo de 21 dias, a medição da distância foi comparada entre grupo controle e laser e, após 6 meses, dentes caninos de ambos os grupos foram radiografados para avaliar qualquer dano radicular ou periodonto adjacente. A velocidade do movimento dos caninos (quantidade de movimento em milímetros dividido pelo tempo passado para realizar o movimento) foi maior no lado experimental (laser) versus o lado controle (não laser) como se observa na figura 3. Esta velocidade foi maior no grupo laser, independente da arcada superior ou inferior. Quanto a avaliação de dor, houve também resultados significativos para a diminuição de dor no lado laser. Os autores concluíram que o laser de baixa potência (GaAlAs) é considerado uma ferramenta eficaz durante o tratamento ortodôntico, com uma taxa de movimento do dente aumentada e o nível de dor reduzido.

Gráfico 1: Efeito da TLBI na velocidade do movimento dentário nos grupos controle e laser

Fonte: Youssef et äl., 2008, p.29

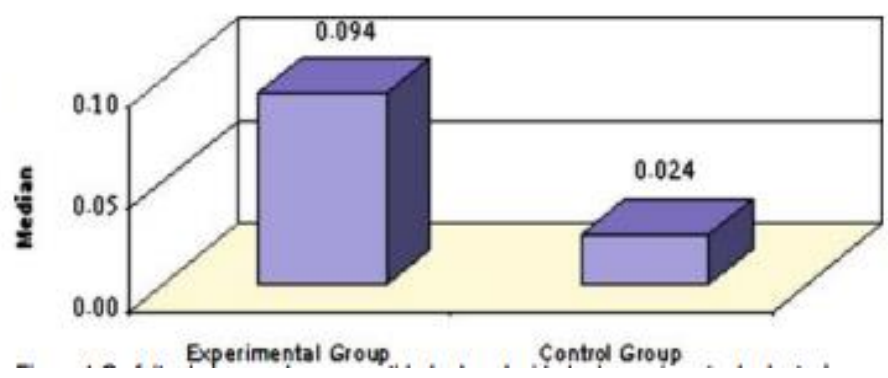

Sousa et al. (2011) realizaram um estudo com objetivo de comparar a velocidade e a quantidade de movimentação ortodôntica de dentes caninos humanos irradiados ou não com laser diodo, bem como para verificar a preservação e integridade do tecido após aplicação do laser. Dez pacientes de ambos os gêneros, com idade média de 13,1 anos e com necessidade de extração de primeiros pré-molares devido a apinhamento ou biprotrusão foram avaliados. No total, avaliaram 26 caninos, 10 superiores e 16 inferiores, divididos em 2 grupos, com 13 dentes no grupo placebo, considerado controle (GC) e 13 no grupo laser (GL). A retração dos caninos iniciou 3 meses após a extração dos primeiros pré-molares e foi avaliada por um período de 4 meses. Foi instalado aparelho ortodôntico com braquetes de prescrição Andrews, de canaleta de 0,022 " por 0,028 " polegadas em caninos e segundo pré-molares e banda ortodôntica nos primeiros molares e unidos por arcos segmentados de aço inoxidável 0,016" em conjunto com uma mola fechada de NiTi proporcionando uma força de retração no canino de $150 \mathrm{~g}$ (T1). As molas foram reativadas após 30 (T2) e 60 (T3) dias. Foram realizadas moldagens em T1, T2, T3 e com 90 dias (T4). Em T1 e T4 foram realizadas radiografias periapicais na técnica da bissetriz. A aplicação de laser foi feita no GL, usando equipamento de laser diodo de baixa potência (GaAlAs), com comprimento de ondas contínuas de $780 \mathrm{~nm}$ em uma área de $0,04 \mathrm{~cm}^{2}$, com saída utilizada de $20 \mathrm{~mW}$ e densidade de energia de $5 \mathrm{~J} / \mathrm{cm}^{2}$ por 10 segundos por ponto, resultando em um total de $0,2 \mathrm{~J}$ por ponto, em 5 pontos distintos na vestibular (figura 5) e 5 pontos distintos na lingual/palatina, perfazendo um total de energia recebida de $2 \mathrm{~J}$ por dente por sessão de 
aplicação. As sessões de aplicação do laser ocorreram depois da instalação/ativação da mola (dia 0), 3 e 7 dias após a primeira aplicação, resultando um total de $6 \mathrm{~J} / \mathrm{mês}$ de energia, em T1, T2 e T3, num total de 9 aplicações em 10 pontos distintos por dente. Os modelos obtidos em T1, T2, T3 e T4 foram escaneados em 3D para medir a movimentação, usando como referências a distância da ponta do canino e a área mais cervical da papila entre os incisivos centrais no lado irradiado (DCPI) e no lado não irradiado (DCP). A retração mensal foi calculada pela diferença entre a DCPI atual e a DCPI do mês anterior e o mesmo com a DCP. Em todos os períodos de avaliação, o movimento do canino foi estatisticamente maior no GL que no GC, com quase o dobro do movimento total (T1-T4). No entanto, pode-se observar que, a medida que o tempo passa, essa diferença diminui, ainda que continue sendo estatisticamente diferente. As radiografias obtidas em T1 e T4 tem como objetivo avaliar a quantidade de reabsorção óssea da crista alveolar e quaisquer possível reabsorção da raiz dos caninos tracionados. Nenhuma diferença estatisticamente significativa foi encontrada na reabsorção de raiz ou crista do osso alveolar entre GC e GL. O estudo conclui que a terapia com laser de baixa potência acelera o movimento ortodôntico de retração de caninos, principalmente no período inicial da retração, provavelmente reduzindo o tempo total do tratamento sem que haja reabsorções radiculares e do osso alveolar.

Figura 3: Pontos de aplicação do laser na superfície vestibular

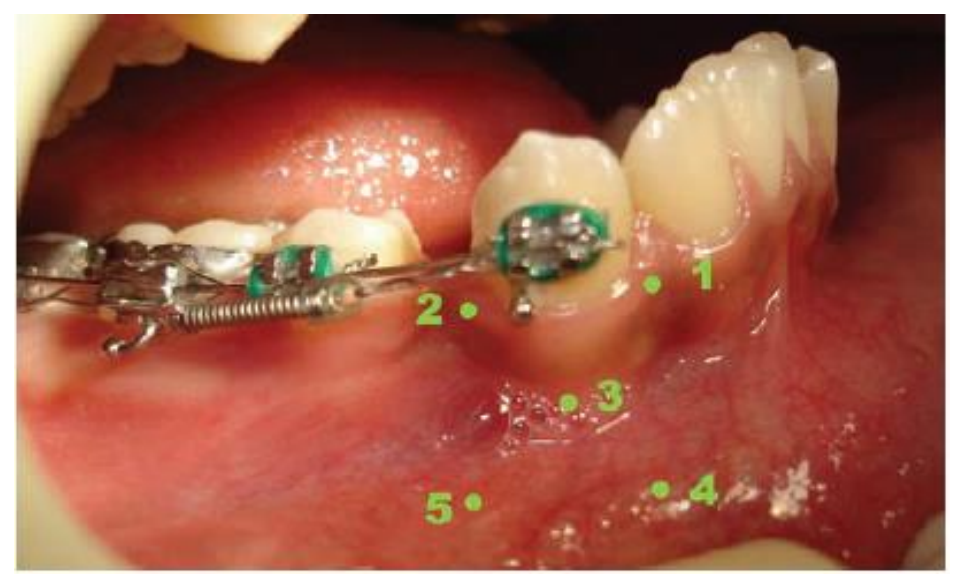

Fonte: Sousa et al., 2011, p.192

Doshi-Mehta e Bhad-Patil (2012) fizeram um estudo para avaliar a eficácia da terapia de laser de baixa intensidade para reduzir o tempo de tratamento ortodôntico e a dor. Sua amostra consistiu de 20 pacientes que necessitavam de extração dos primeiros pré-molares, de ambas as arcadas. Os pacientes foram divididos aleatoriamente em 2 grupos, grupo 1 controle e grupo 2 experimental, e o modelo de estudo foi de boca dividida, para evitar a variação interindividual biológica. Cada grupo consistiu de 30 quadrantes. No (sétimo) $7^{\circ}$ dia após as extrações, foram colocadas bandas nos molares com tubos triplos e duplos, na arcada superior e inferior respectivamente e, para reforço de ancoragem, confeccionado barra transpalatina e arco lingual com fio de aço de $0,9 \mathrm{~mm}$. Foram colados braquetes com slot de 0,022 e para alinhamento e nivelamento fios 0, $016 \mathrm{NiTi}$, posteriormente 16x22 NiTi, 17x25 NiTi, 17x27 aço e 19x25 NiTi. Após concluído essa etapa, um fio 19x25 em aço foi colocado como fio de trabalho e 21 
dias após sua colocação foi iniciada a retração do canino com mola helicoidal fechada de NiTi. Os incisivos foram conjugados com ligadura de fio de aço 0,009, bem como os primeiros molares e segundos pré-molares para fazer uma única unidade de ancoragem. Uma força de $150 \mathrm{~g}$ constante foi aplicada para a retração em ambos os grupos e a terapia a laser de baixa intensidade iniciou-se no mesmo dia que a mola foi colocada. $\mathrm{O}$ laser usado foi um semicondutor GaAlAs), emissor de radiação infravermelha, com comprimento de onda de $808 \mathrm{~nm}, 10 \mathrm{~mW}$. Para analgesia, o comprimento de onda foi ajustado para $800 \mathrm{~m}$, modo contínuo, potência de $0,7 \mathrm{~mW}$ e 10 segundos de exposição. A terapia a laser iniciou-se no dia da instalação da mola e duas irradiações foram feitas, no terço médio da raiz do canino, pelo lado bucal e palatino, para efeito analgésico. No dia 3 , a terapia iniciou para bioestimulação, com um total de 10 irradiações, 5 no lado bucal e 5 no lado palatino, seguindo a distribuição de 2 doses no terço cervical da raiz do canino, 2 doses no terço apical (ambas mesial e distal) e 1 no terço médio (centro da raiz). O regime de laser foi aplicado nos dias $0,3,7$ e 14 no primeiro mês e depois todos os dias até a retração completa do canino do lado experimental. Após 6 meses, radiografias foram realizadas para averiguar alguma alteração indesejável no osso alveolar, ligamento periodontal e raízes, bem como foram feitos testes de vitalidade nos caninos. Três modelos foram feitos para cada paciente e medidos com paquímetro digital tendo como pontos de referência a ponta da cúspide mesial do primeiro molar e o canino. As distâncias foram registradas a T0 (após a conclusão do alinhamento e nivelamento): dia 1 de retração do canino, T1 (3 meses de retração), e T2 (conclusão da retração do lado experimental). A taxa de movimento ortodôntico foi calculada como a quantidade de movimento do dente dividido pelo período de tempo, sendo assim, ao final de 3 meses (M1), foi o registro de T0-T1 dividido por 3 e a taxa de movimento ortodôntico de retração (M2), que é T1-T2 dividido pelo número de meses. Houve um aumento significativo na taxa de movimentação do lado experimental versus o controle, em M1, foi 0,65 mm por mês no lado controle e 1,46 no lado experimental e em M2, $0,81 \mathrm{~mm}$ controle e 1,15 experimental. Além disso, a pontuação de dor no lado experimental também foi significativamente menor que o controle, mensurado através da escala analógica visual de dor (figura 8). Concluiu-se que a TLBI aumenta a taxa de movimento ortodôntico de forma fisiológica, sem causar efeitos colaterais nos dentes e periodonto e, dessa forma, encurta o tempo de tratamento; além disso, promove analgesia durante o tratamento de forma muito eficaz. 
Figura 4: Escala visual analógica de dor

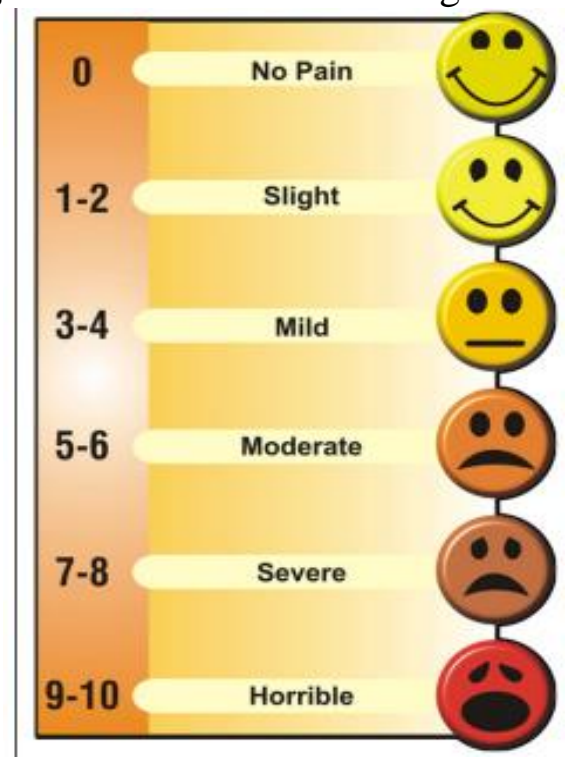

Fonte: Doshi-Mehta e Bhad-Patil, 2012, p. 293.

Long et al. (2013) realizaram uma revisão sistemática para avaliar a eficácia das intervenções na aceleração do movimento ortodôntico. Foram pesquisados os bancos de dados PubMed, Embase e Science Citation Index, sites de Cochrane Central Register de Ensaios Controlados (CENTRAL) e o banco de dados de literatura cinzenta (SINGLE). A pesquisa eletrônica foi a partir de 01 de janeiro de 1990 a 20 de agosto de 2011, sem restrições de linguagem. Foram selecionados apenas estudos sob tratamento ortodôntico convencional, sem qualquer melhoria de ancoragem. Foram avaliadas a terapia a laser de baixa potência, que é seguro em relação ao tecido periodontal e raiz, mas inconclusivo para acelerar o movimento ortodôntico; corticotomia, que é uma intervenção relativamente segura e eficaz para acelerar o movimento; corrente elétrica, campos eletromagnéticos pulsados, no que diz respeito a metodologia confiável e resultados, ambas não são eficazes para acelerar; e distração dentoalveolar é seguro e diante das metodologias e resultados limitados são eficazes para acelerar o movimento ortodôntico. Excluindo a corticotimia, as outras técnicas carecem de evidências mais convincentes.

Ge et al. (2015) realizaram uma revisão sistemática e meta-análise para avaliar a eficácia da aceleração da movimentação ortodôntica através da aplicação de laser de baixa potência. Uma extensa pesquisa eletrônica foi realizada no banco de base de dados CENTRAL, PubMed, MEDLINE, China National Knowledge Infrastructure (CNKI) e China Biology Medicine Disc (CBM) entre janeiro de 2013 até fevereiro de 2013. Com base nos critérios de seleção e exclusão adotados, 9 artigos foram incluídos (tabela 1). Nessa revisão, a aplicação do laser de baixa intensidade aumentou estatisticamente a distância percorrida pelo dente nos períodos de 7 dias, 2 meses e 4,5 meses, ao passo que não foi observada diferença significativa entre o grupo teste e o grupo controle no período de 1 mês. Fica demonstrado que a laserterapia pode acelerar o movimento do dente em tratamento ortodôntico, nenhum efeito adverso foi detectado e uma densidade de radiação entre $2,5,5$ e $8 \mathrm{~J} / \mathrm{cm}^{2}$ aparentemente são mais eficazes que doses entre 20 e $25 \mathrm{~J} / \mathrm{cm}^{2}$, ainda que a dose ótima manteve-se indeterminada. 
Tabela 1: Parâmetros dos tratamentos e dos equipamentos laser incluídos no estudo

\begin{tabular}{|c|c|c|c|c|}
\hline estudo ID & Tipo de laser & $\begin{array}{l}\text { Comprimento de anda } \\
\text { I densidade de energia }\end{array}$ & $\begin{array}{l}\text { Salda de pottencia / } \\
\text { tempo botal por dente } \\
\text { (s) }\end{array}$ & Frequencia do tratamento a laser \\
\hline \multirow{2}{*}{\multicolumn{2}{|c|}{ Limpanichkul 2006 uma | 26 ] Tallandia GaAlAs laser semicondutor diodo }} & $860 \mathrm{~nm}$ & $100 \mathrm{~mW}$ & Dias $1,2,3$ de cada mês \\
\hline & & $25 \mathrm{~J} / \mathrm{cm} 2$ & $184 \mathrm{~s} /$ dente & Por 3 meses \\
\hline \multirow[t]{2}{*}{ Gui 2008 ma [ 25 ] China } & laser semicondutor GaAs & $650 \mathrm{~nm}$ & $20 \mathrm{~mW}$ & Uma vez por semana \\
\hline & & $25 \mathrm{~J} / \mathrm{cma}$ & $1.200 \mathrm{~s}$ & Durante 4 semanas \\
\hline \multirow[t]{2}{*}{ Doshi-Mehta 2012 ma 23 ] India } & GaAlAs laser semicondutor diodo & $810 \mathrm{~nm}$ & $80 \mathrm{~mW}$ & Dias $0,3,7,14$ em cada 15 dias \\
\hline & & $20 \mathrm{~J} / \mathrm{cma}$ & $100 \mathrm{~s} /$ dente & Para 4,5 meses \\
\hline \multirow[t]{2}{*}{ Youssef $2008 \mathrm{bt} 30$ ] Siria } & GaAlAs laser semicondutor diodo & $809 \mathrm{~nm}$ & $100 \mathrm{~mW}$ & Dias $0,3,7,14$ de cada etapa ( 3 semanas) \\
\hline & & $8 \mathrm{~J} / \mathrm{cms}$ & $80 \mathrm{~s} /$ dente & Para 3 fases ( 9 semanas) \\
\hline \multirow[t]{2}{*}{ Cruz 2004 bt 22 ] Brasil } & GaAlAs laser semicondutor diodo & $780 \mathrm{~nm}$ & $20 \mathrm{~mW}$ & Dias $0,3,7,14$ de cada mês \\
\hline & & S.J/ $\mathrm{cms}$ & $100 \mathrm{~s} /$ dente & Por 2 meses \\
\hline \multirow[t]{2}{*}{ Wang 2007 b 28 ] China } & GaAlAs laser semicondutor diodo & $780 \mathrm{~nm}$ & $20 \mathrm{~mW}$ & Uma vez por semana \\
\hline & & S J J / cms & $100 \mathrm{~s} /$ dente & Por 8 semanas \\
\hline \multirow[t]{2}{*}{ Sousa 2011 b 27 ] Brasa } & GaAlAs laser semicondutor diodo & $780 \mathrm{~nm}$ & $20 \mathrm{~mW}$ & Dias $0,3,7$ de cada mês \\
\hline & & S J J / cms & $100 \mathrm{~s} /$ dente & Para 4 meses \\
\hline \multirow[t]{2}{*}{ Xu de 2008 [ 29] China } & Ele - Leer de $\mathrm{Ne}$ com $\mathrm{CO}_{2}$ a laser assi & & $20 \mathrm{~mW}$ & Dias $1,2,3,4,5$, em 21 dias \\
\hline & & $2,5 \mathrm{~J} / \mathrm{cm} 2$ & & \\
\hline \multirow[t]{2}{*}{ Fujyama 2008 [ 24 ] Jap8̊ } & $\mathrm{CO}_{2}$ laser, 5 pulsos por $s 1.000$ & \multicolumn{2}{|l|}{ Não especificado 2 W } & Uma ver que (imediatamente apds a separacalo) \\
\hline & & & $60 \mathrm{~s} /$ dente & \\
\hline
\end{tabular}

Fonte: Ge et al., 2015, p. 1613

Dominguez et al. (2015) fizeram um estudo para avaliar a eficácia da TLBI quanto ao movimento dentário, receptor de fator nuclear (RANKL), osteoprotegerina (OPG) no fluido gengival (GCF) no lado de compressão e dor durante o tratamento ortodôntico. O estudo consistiu de 10 indivíduos, com idade entre 12 e 16 anos e com indicação clínica de extração do segundo pré-molar superior. $O$ hemiarco superior direito foi designado como grupo laser e o hemiarco esquerdo foi designado como grupo controle. O tratamento ortodôntico foi iniciado 2 semanas após as extrações e, para alcançar o máximo de ancoragem posterior, os pacientes receberam um arco de Nance, cimentado nos primeiros molares, como na figura 12a. Um arco de fio de aço de $0,16 \mathrm{~mm}$ foi colocado entre primeiro pré-molar e o primeiro molar superior, como na figura 12b. Este arco foi preso por amarrilhos e a retração foi feita por uma mola fechada de NiTi com força constante de $150 \mathrm{~g}$ medida por um dinamômetro. O dispositivo de laser de diodo usado operava em 670nm de comprimento de onda, potência de saída de $200 \mathrm{~mW}$, onda contínua $6,37 \mathrm{~W} / \mathrm{cm}^{2}$ e a aplicação do laser foi realizada pela ponta de difusão de luz que foi parcialmente inserida dentro da bolsa gengival. A radiação foi aplicada na distal, vestibular e lingual do primeiro pré-molar (3 minutos cada superfície, 9 minutos no total) nos dias $0,1,2,3,4$ e 7 . Foram obtidos modelos de gesso a partir de moldagens com alginato realizadas nos dias $0,2,7,30 \mathrm{e}$ 45. Esses modelos foram digitalizados e, através de um software, a distância entre a ponta da cúspide mesiovestibular do primeiro molar e a ponta da cúspide do primeiro pré-molar foi medida. Trinta dias após a colocação do aparelho ortodôntico, foi encontrada diferença estatística entre os grupos, mostrando um movimento de retração 
maior no grupo do laser. Não foi encontrada diferença estatística significante na concentração de GCF de RANKL e OPG, ainda que níveis de RANKL em GCF e RANKL/OPG estavam aumentados em comparação ao grupo controle. O estudo relata ligeira redução de dor com uso de LBI.

Figura 05: Dispositivos usados para a movimentação ortodôntica

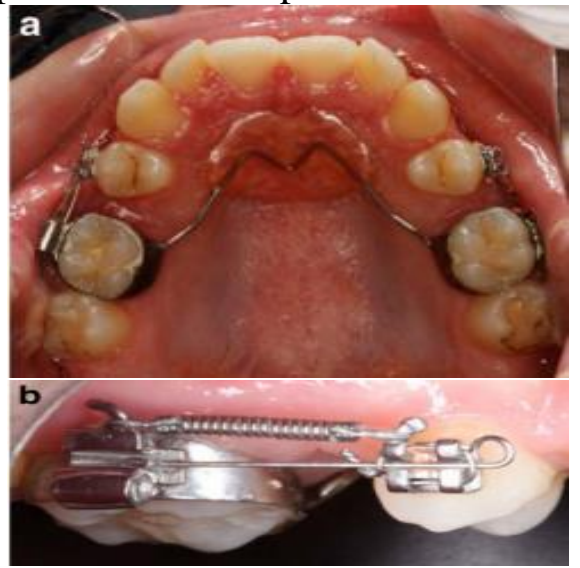

Legenda: a) Ancoragem posterior feita com arco de Nance; b) Mola helicoidal fechada de NiTi

Fonte: Dominguez et al., 2015, p. 917.

Seifi e Vahid-Dastjerdi (2015) realizaram uma revisão de literatura sobre os diferentes aspectos do uso do LBI no movimento ortodôntico e suas alterações. Foram pesquisados na base de dados eletrônicas de PubMed e ScienceDirect de Janeiro de 2009 a agosto de 2014. Também foram pesquisados Google Scholar e literatura cinzenta. Dados gerais sobre o estudo foram: tamanho da amostra, comprimento de onda $(\mathrm{nm})$, potência $(\mathrm{mW})$ e duração. $\mathrm{O}$ efeito bioestimulante do laser de baixa potência tem sido mostrado em diferentes estudos, mas os resultados experimentais diferentes produziram muitas questões controversas e demonstram uma grande variabilidade, vide tabela 2. Concluiu-se que há evidências deque o laser de baixa potência acelera o processo de remodelação óssea, estimulando a proliferação e função de células osteoblásticas e osteoclásticas durante movimento ortodôntico, bem como há evidências do não movimento e essas diferenças estatísticas podem ser entre a baixa e alta energia nos lados experimentais e controle, respectivamente. 
Tabela 2: Informações sobre os estudos incluídos

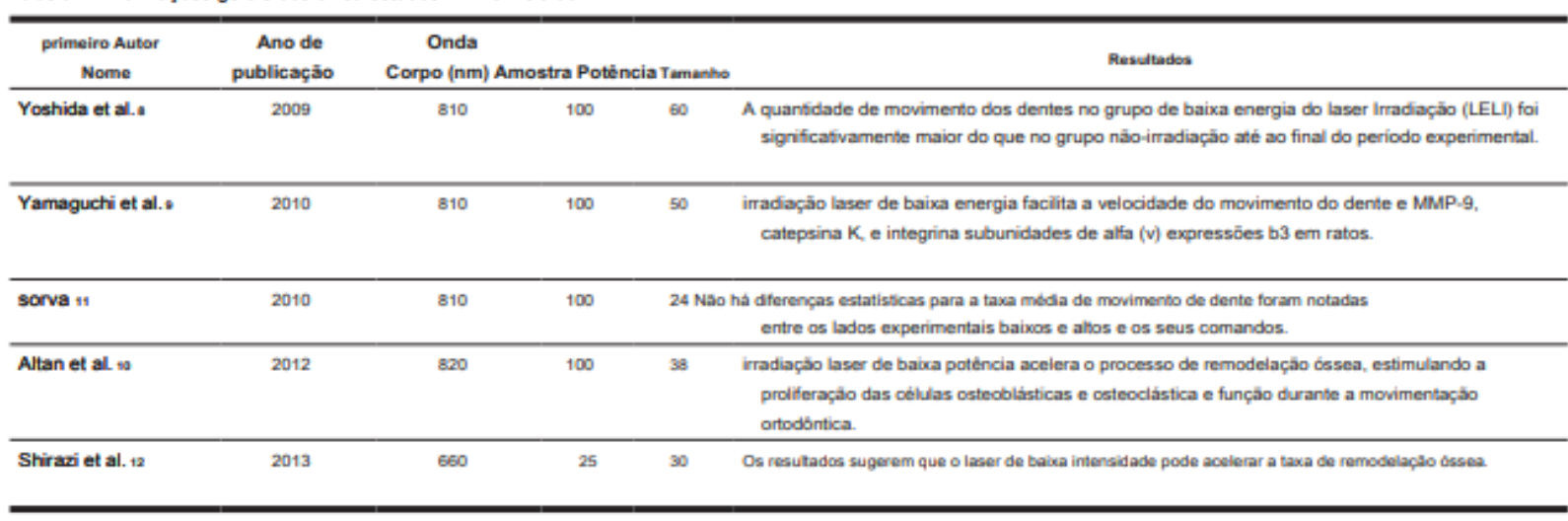

Fonte: Seifi e Vahid-Dastjerdi, 2015, p.4.

Long et al. (2015) realizaram uma meta-análise que tinha como objetivo a avaliação crítica das evidências atuais e determinar a eficácia da terapia a laser de baixa intensidade na aceleração do movimento ortodôntico. As bases de dados usadas foram PubMed, Web of Knowledge, Embase, CENTRAL, ProQuest Dissertações e Teses e SINGLE a partir de janeiro de 1990 a junho de 2013, e cinco estudos foram selecionados entre eles, ensaios clínicos randomizados (4 RCT) e ensaios clínicos controlados (1 CCT); no entanto, encontrou-se a heterogeneidade e a instabilidade nos resultados. Todas as amostras do estudo apresentavam de 11 a 20 participantes, idade entre 12 e 23 anos, e retração de caninos e medições em 1, 2 e 3 meses após início da mecânica de retração. Os diferentes comprimentos de onda e potências de irradiação de laser de saída podem explicar a heterogeneidade detectada em todos os estudos e a ancoragem posterior foi muito importante para a precisão dos dados (tabela 3). Foram usados comprimentos de onda de 650,780, 800 e 860nm e na meta-regressão revelou uma correlação negativa entre movimento dentário e comprimento de onda; no entanto, devido à falta de dados suficientes, só podemos analisar um subgrupo de comprimento de onda de 780nm. Os resultados, no primeiro, mês foram insignificantes na maioria dos estudos e isto pode ser devido a mais suscetíveis erros de medição. Sugere-se que a TLBP foi eficaz para acelerar o movimento ortodôntico com comprimento de onda $780 \mathrm{~nm}$, fluência de $5 \mathrm{~J} / \mathrm{cm}^{2}$ e potência de $20 \mathrm{mw}$ em 2 e 3 meses. A eficácia em outros comprimentos de onda (650 e $800 \mathrm{~nm}$ ), densidades e potências neste estudo contiveram dados insuficientes para determinar alta qualidade de evidências.

Tabela 3: Informações gerais dos estudos incluídos

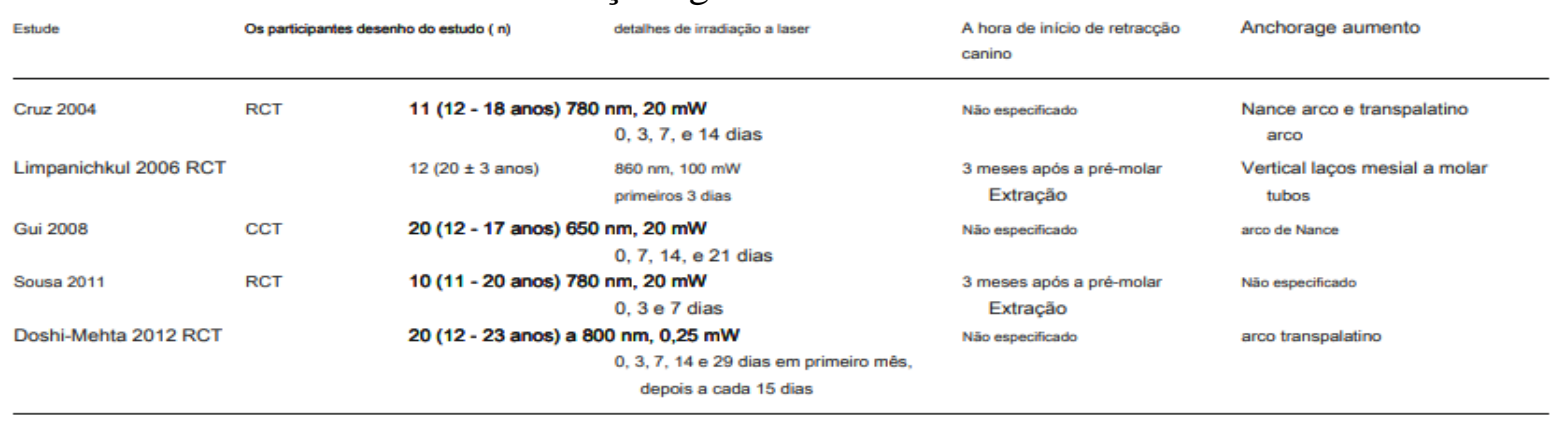

Fonte: Long et al., 2015, p. 1164. 
Qamruddin et al. (2015) realizaram esta revisão sistemática de artigos que pesquisaram procedimentos minimamente invasivos e não invasivos realizados para acelerar a movimentação ortodôntica em animais. Foram avaliados artigos publicados de janeiro de 2009 até 31 de dezembro de 2014. Apenas pesquisas in vivo realizadas em animais e com procedimentos não invasivos ou minimamente invasivos para acelerar a movimentação ortodôntica foram incluídos. Na modalidade dos procedimentos não invasivos, duas pesquisas foram baseadas no uso de laser de baixa intensidade (LBI), 1 artigo avaliou vibração mecânica, 2 artigos relataram uso de ultrassom pulsado de baixa intensidade (LIPUS) e 1 artigo estudou o efeito da LBI com piezocisão. Na modalidade dos procedimentos minimamente invasivos, todos os trabalhos avaliaram corticocisão sem retalho com abordagens com pouca diferença entre eles, sendo 3 trabalhos com faca piezoelétrica, 1 com corticocisão a laser e 1 com corticotomia sem retalho usando broca. Pode-se concluir, com esta revisão, que LBI e corticotomia sem retalho apresentam alguma evidência de aceleração na movimentação ortodôntica. No entanto, ainda não há protocolos definidos para os procedimentos. LIPUS e vibração mecânica parecem promissores; mas, devido ao pequeno número de estudos, não foi possível chegar a qualquer conclusão.

Dalaie et al. (2015) realizaram um estudo para avaliar o efeito da irradiação com laser de baixa potência sobre a taxa de movimentação ortodôntica e a dor associada ao início da movimentação de caninos para o local da extração de pré-molares. Este estudo clínico duplo cego randomizado contou com 12 pacientes, sendo nove mulheres e três homens, com idade média de 20,1 anos. Os pacientes incluídos no estudo tiveram os primeiros pré-molares superiores e inferiores extraídos, com os dentes alinhados e nivelados, sem ausências prévias de caninos e pré-molares, para depois de 3 meses começar a distalização do canino. A fase inicial do tratamento consistiu em alinhamento e nivelamento, usando sistema MBT com slot de 0,022 polegadas. Os caninos foram então retraídos utilizando alças de arco seccionado de fios de aço de 16x22 (figura 15), com comprimento de $5 \mathrm{~mm}$ e $7 \mathrm{~mm}$ no arco superior e inferior respectivamente, e uma força de 150 gramas. Os loops foram ativados a cada mês. A medição do movimento foi obtida nos dias 1, 3, 7, 30,33,37,60, 63 e 67, usando um compasso digital, desde a ponta da cúspide canino e da cúspide mésiovestibular do primeiro molar. Os pacientes do grupo teste receberam irradiação laser de baixa potência GaAlAs $(880 \mathrm{~nm}, 5 \mathrm{~J} / \mathrm{cm} 2)$ em 8 pontos por 10 segundos, nos terços cervical, médio e apical das raízes dos caninos, por face vestibular, lingual/palatal e ângulos distopalatal e distovestibulares. O nível de dor foi registrada por "Wong-Baker faces pain rating scale". O efeito da irradiação laser sobre a quantidade de movimentação dentária não foi estatisticamente significativo e a quantidade de movimento em mandíbula e maxila foi a mesma. Não se observou diferença significativa de dor entre o grupo laser e o grupo controle. De acordo com os resultados do presente estudo, não há evidência que o laser de diodo de baixa intensidade aumente a taxa de movimentação ortodôntica ou reduza a incidência de dor associada à movimentação. 
Figura 6 : Alças de arco seccionado de fios de aço
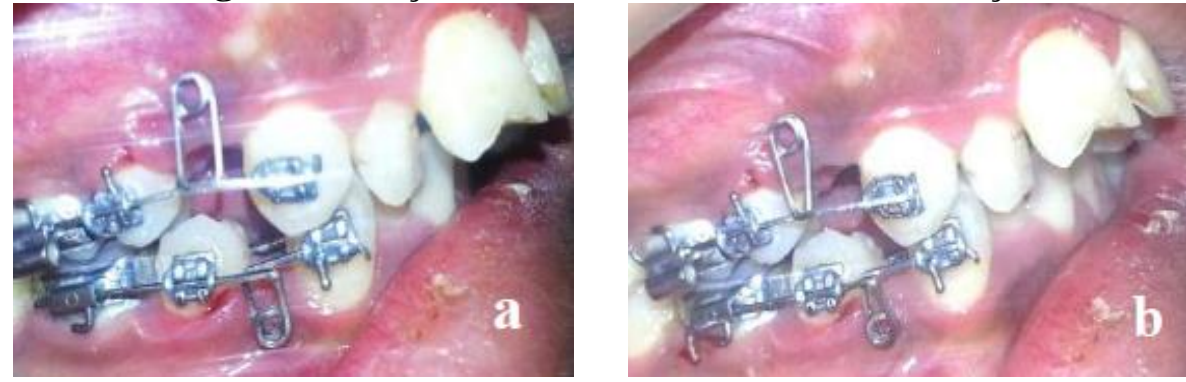

Legenda: a) alça antes da ativação; b) alça ativada $1 \mathrm{~mm}$ para a distal.

Fonte: Dalaie et al., 2015, p.250.

Sonesson et al. (2016) realizaram esta revisão sistemática para investigar se há embasamento científico que justifique o uso de laserterapia de baixa intensidade (LBI) para acelerar o movimento dentário, para prevenir recidivas e para modular dor aguda durante o tratamento ortodôntico com aparelhos fixos em adultos e crianças. Para este trabalho, foram usadas as bases de dados da Medline(via PubMed), The Cochrane Controlled Clinical Trials Register and Scitation. A pesquisa foi até a data 27/11/2015. Em relação a aceleração de movimentação, foram incluídos 3 estudos, sendo que dois deles relataram um aumento significativo na velocidade de movimento. Um estudo mostrou um aumento de velocidade de $30 \%$ no grupo LBI em comparação ao grupo controle, outro estudo mostrou aumento de $27 \%$ na maxila e $30 \%$ na mandíbula e o terceiro estudo mostrou que não houve qualquer aumento de velocidade de movimentação dental. Em relação a prevenção de recidivas, os autores não encontraram qualquer estudo relevante correspondente aos critérios de inclusão. Esta revisão sistemática conta com 13 estudos, sendo que 11 deles relatam redução estatisticamente significante na dor relatada em pacientes submetidos a LBI. Dois estudos não encontraram diferenças na sensação de dor. Nesta revisão sistemática, os autores concluem que as evidências de aceleração de movimentação ortodôntica com LBI são de baixa qualidade, assim como as evidências de modulação de dor aguda com LBI também são de baixa qualidade. Nenhum estudo preencheu os critérios de inclusão sobre prevenção de recidiva ortodôntica com aplicação de LBI.

Almpani e Kantarci (2016) avaliaram os métodos não-cirúrgicos para aceleração do movimento ortodôntico, entre eles a irradiação de laser de baixa intensidade. Com base na literatura, eles comparam o uso sistêmico de substâncias químicas: fator de crescimento epidérmico, hormônio da paratireóide, vitamina D3, tiroxina, osteocalcina e prostaglandinas. Estudos associam o uso dessas substâncias com um risco aumentado de reabsorção radicular e dor. Foi estudada também terapia de transferência de genes, que consistem em um método alternativo para administrar proteínas num tecido alvo e, por sua vez, melhorar o recrutamento de osteoclastos e conduzir a um movimento ortodôntico acelerado. Comparam também relaxina, ressonância de vibração, correntes elétricas, campo magnético pulsado ou estático, fotobiomodulação ou terapia de luz de baixo nível e radioterapia laser de baixa intensidade. Essas técnicas de estimulação física são menos propensas a efeitos adversos e livres de dor; portanto, mais atrativas para os pacientes, mas são necessários protocolos de aplicação mais eficientes e evidências científicas para a introdução na prática clínica. Concluiram que não importa quão pequena seja a cirurgia, os métodos não cirúrgicos são preferíveis pelos pacientes ortodônticos pelos efeitos colaterais que podem estar sujeitos e custos adicionais. 
Almeida et al. (2016) realizaram esta revisão sistemática e meta-análise para investigar as evidências científicas que demonstrem a eficácia do laser de baixa intensidade (LBI) na aceleração da movimentação dentária durante tratamento ortodôntico. Para este trabalho, foram pesquisadas as bases de dados online PubMed, Scopus, SciELO, Lilacs, BBOe OpenGrey, no período de 1/5/2015 a 25/9/2015, com base na metodologia PRISMA. Não foram incluídas pesquisas com animais, revisões de literatura e relatos de casos. Após este levantamento inicial, 98 artigos foram identificados, mas apenas 6 deles preencheram os requisitos e puderam ser incluídos neste estudo. Estes artigos foram publicados entre 2004 e 2014. Todos os estudos usaram o mesmo tipo de laser (GaAlAs), com baixa densidade de energia, aplicados em regiões vestibulares e palatinas em área adjacente ao canino a ser retraído. Este estudo conclui que a quantidade de aplicações de LBI não é um fator determinante da eficácia da aceleração do movimento dental. Concluiu-se também que o período de tempo em que o LBI foi aplicado não é um fator determinante sobre a aceleração do movimento dentário. Por fim, ao realizar esta revisão sistemática e meta-análise, os autores concluíram que não há evidências que o uso de LBI cause indução de aceleração de movimento dentário e que mais estudos clínicos randomizados com amostra maior são necessários para aumentar a credibilidade das provas sobre os efeitos da TBI em acelerar a movimentação dental em ortodontia.

Suzuki et al. (2016) avaliaram a influência da terapia laser de baixa intensidade (TLBI) sobre o metabolismo ósseo, da movimentação dentária e das reabsorções radiculares nos dias $0,3,6,9,14$ e 21 dias. Foram realizadas histomorfometria do osso alveolar, imuno-histoquímica e análise da estrutura óssea volumétrica e análise das reabsorções radiculares através de microscopia de varredura. Sessenta e oito ratos foram usados nas experiências. Foi instalado um parafuso por trás dos incisivos superiores e uma mola helicoidal de NiTi foi usada entre o parafuso e o primeiro molar superior esquerdo para criar uma força de $50 \mathrm{~g}$ para mover o molar em direção ao parafuso. Os resultados mostraram que o grupo TLBI demonstrou maior movimento do dente ao longo do período experimental, quando comparado ao grupo controle, em todos os períodos estudados. O estudo sugere que o TLBI pode acelerar a velocidade de movimentação dentária através do aumento da atividade de células osteoclásticas, estimulando o processo de reabsorção óssea no lado da compressão e, em consequência, levou a uma redução das lacunas de reabsorção radicular. Além disso, a TLBI pode ter um efeito positivo sobre a formação de osso no lado de tensão.

Gonçalves et al. (2016) fizeram um estudo para avaliar os eventos celulares envolvidos durante o processo de movimento do dente, a fim de elucidar os mecanismos específicos envolvidos neste processo, bem como estabelecer o número de irradiações e o tratamento mais adequado para fotobiomodulação (FBM) eficaz. Para isso, usou 72 ratos Wistar e estes foram distribuídos aleatoriamente em dois protocolos, com ou sem aparelho ortodôntico (AO). E cada protocolo em 3 subgrupos: com uma sessão de terapia a laser, com três sessões de terapia a laser e não foram submetidos a terapia. $\mathrm{O}$ aparelho ortodôntico consistia de uma mola de 0,016 " de aço, soldada e fixados a direita e esquerda dos incisivos em cada borda uma banda ortodôntica. O laser de baixa intensidade usado foi um semicondutor de GaAlAs, numa dose de energia de $10 \mathrm{~J} / \mathrm{cm}^{2}$, onda contínua, $40 \mathrm{~mW}$, tempo de 10 segundos e comprimento de onda de 780nm. Após 7 ou 14 dias, a distância interincisiva foi medida com compasso e foram feitas análises estatísticas dos resultados do início do movimento e os ratos foram sacrificados para fazer uma avaliação histológica e histomorfométrica, investigando células 
osteoblásticas, deposição de matriz de colágeno, e volume de tecido ósseo formado. Verificou-se, nos grupos laser com AO, um aumnto da área óssea recém-formada em torno dos incisivos centrais em contraste com grupo não laser. Também é importante ressaltar o aumento do número de células osteoblásticas e do teor de colágeno na mesma região. Em resumo, os presentes resultados sugerem que a FBM pode acelerar o movimento ortodôntico acompanhada de remodelação óssea e efeitos positivos no tecido, tal como aumento do número de osteoblastos e área de novo osso formado.

Farsail A. e Al-Jewair T. (2017) realizaram esta revisão sistemática para investigar se há evidência científica que embase a aplicação de laser de baixa intensidade (LBI) na aceleração da movimentação ortodôntica, na prevenção da recidiva ortodôntica e na modulação da dor aguda decorrente do tratamento ortodôntico. Para identificar os estudos relevantes foram pesquisadas as bases de dados do Medline, Cochrane Controlled Clinical Trials Register e a seleção seguiu o Preferred Reporting Itens for Systematic and Meta-analysis (PRISMA). Um total de 16 estudos foram incluídos, sendo 3 estudos de aceleração de movimentação de dente por LBI e 13 sobre o efeito da LBI na modulação da dor aguda. Dos 3 estudos incluídos sobre aceleração de movimentação com LBI, dois deles relatam que há aproximadamente $30 \%$ de aceleração em comparação ao grupo controle e o terceiro estudo relata não haver diferença estatística entre os grupos. Dos 13 estudos incluídos sobre modulação de dor aguda, 11 relatam redução estatisticamente significativa de dor referida dos pacientes submetidos a aplicação de LBI. No entanto, outros 2 estudos não encontraram diferenças na sensação de dor relatada. Não encontraram estudos referentes a aplicação de LBI na prevenção de recidiva ortodôntica. Esta revisão sistemática concluiu que a qualidade das provas que sustentam a aplicação de LBI para acelerar a movimentação ortodôntica é muito baixa e a qualidade das provas que sustentam a aplicação de LBI para modular a dor aguda é baixa. Isto sugere a necessidade de mais pesquisas de qualidade superior para determinar se a LBI pode acelerar e reduzir a dor do tratamento ortodôntico em crianças e adultos.

Miles P (2017), em revisão de literatura, examinou técnicas cirúrgicas e não cirúrgicas de aceleração de movimentação ortodôntica e o nível de evidências científicas disponíveis. Em sua revisão, não encontrou diferença de tempo de tratamento com braquetes auto-ligados em comparação a braquetes convencionais e a escolha de um deles reflete a preferência do paciente e do profissional. Há evidência de que o laser de baixa intensidade acelera a movimentação. Outras técnicas não cirúrgicas foram vistas, como o uso de medicação sistêmica para alterar a resposta biológica dos pacientes, uso de energia piezoelétrica para induzir uma resposta odontogênica, fotobiomodulação, campos eletromagnéticos e correntes elétricas locais para modificar a biologia celular, sendo que nenhuma delas apresentou evidências fortes que sustentem seu uso. Os procedimentos cirúrgicos revisados foram a perfuração micro-óssea, cirurgia óssea periodontal, osteotomia e corticotomia, sendo esta última a que parece mostrar mais evidências de eficácia de aceleração; mas, como as evidências ainda são pobres, mais investigações são necessárias.

Milligan et al. (2017) compararam a quantidade de movimentação dentária, alteração de expressão gênica no ligamento periodontal em área de remodelação óssea e alterações histológicas na gengiva adjacente aos dentes movimentados. Contaram com 27 ratos, divididos em 3 grupos, sendo um grupo controle (CT, n=8), e dois grupos experimentais, submetidos a 500mW (EX-500, $n=10)$ e $1000 \mathrm{~mW}(\mathrm{EX}-1000, \mathrm{n}=9)$ de irradiação de laser de baixa potência (LBI). Sob anestesia geral, todos os ratos dos 3 
grupos receberam uma mola instalada entre o primeiro molar e os incisivos com $10 \mathrm{~g}$ de força por 14 dias para induzir a mesialização do molar. As molas foram verificadas e ativadas a cada 2 dias. Nos grupos experimentais, foi utilizado laser de diodo Picasso Lite, AMD Lasers, Dentsply, GAC, de comprimento de onda de $810 \mathrm{~nm}$, sendo 500mW no grupo EX-500 e 1000mW no grupo EX-1000, ambos com fibra ótica de diâmetro de $0,4 \mathrm{~mm}$ a $1 \mathrm{~mm}$ da gengiva, com movimentos circulares por 24 segundos na palatina e 48 segundos na vestibular. Para medir a movimentação dentária, foram realizadas moldagens nos dias de ativação do aparelho e no fim do experimento; as moldagens visualizados no microscópio de dissecção e as distâncias foram medidas com paquímetro eletrônico por dois observadores diferentes. Após 14 dias, a movimentação média foi de $0,639+-0,057 \mathrm{~mm}$ para CT, 0,745+-0,051mm para EX-1000 e 0,753+0,057mm para EX-500 um aumento estatisticamente significativo foi observado para o grupo EX-500 em comparação ao CT. Não houve diferença estatística entre EX-1000 e CT e entre EX-500 e EX-1000. No fim das movimentações dentárias, os ratos foram sacrificados e os primeiros molares esquerdos foram extraídos e armazenados para subsequente coleta de células do ligamento periodontal para RT-qPCR, técnica que permite verificar a expressão gênica através do RNA. O tecido palatino adjacente ao dente extraído foi excisado e preparado por hematoxilina e eosina (H\&E) e coloração Masson, para avaliar número e morfologia das células epiteliais e fibroblastos comparando os 3 grupos. Embora nenhuma necrose tissular tenha sido encontrada, alterações epiteliais e conjuntivas foram encontradas no grupo EX-1000, sugestivas de hiperplasia epitelial e aumento de proliferação celular da camada basal. No grupo EX500, não foi observado alteração histológica epitelial significativa em comparação ao CT. O tecido conjuntivo demonstrou alteração em ambos os grupos teste, com maior número de fibroblastos, em comparação ao CT e está de acordo com a literatura. A análise quantitativa da expressão gênica foi realizada através da raspagem do ligamento periodontal da superfície dos dentes extraídos e extração do RNA. O RNA foi convertido em cDNA, diluído e submetido a ensaio qRT-PCR para GAPDH, RANKL, e MMP-13. As expressões RANKL e MMP-13 foram reguladas para cima em ambos os grupos experimentais em relação ao CT, sendo significativamente maiores no EX-1000 em comparação ao CT e no EX-500 em comparação ao CT, não havendo diferença estatística significativa entre os dois grupos experimentais para RANKL e MMP-13. As expressões de RANKL e MMP-13 puderam ser moduladas pela terapia laser; mas; por não haver diferença estatisticamente significativa de movimentação dentária entre os grupos CT e EX-1000, o significado clínico desta modulação não é claro. Este estudo demonstrou que, na terapia laser, a potência é um parâmetro crítico sobre a quantidade de movimentação dentária, uma vez que ela exerce um processo de remodelação óssea distinto nos tecidos do ligamento periodontal além de alterações displásicas na gengiva adjacente. Conclui-se, então, que a terapia laser pode acelerar a movimentação dentária em ortodontia, mas mais estudos precisam ser realizados para estabelecer um protocolo clínico ideal para maximizar o efeito desejado encurtando o tempo de tratamento e minimizar os efeitos indesejáveis nos tecidos moles.

Alsayed Hasan et al. (2017) realizaram um estudo randomizado e controlado, entre julho de 2015 e março de 2016 para avaliar a eficácia do LBI na aceleração do movimento ortodôntico dos incisivos superiores apinhados. O estudo consistiu de 26 pacientes com grande apinhamento na região dos incisivos superiores e com indicação de extração dos primeiros pré-molares. Cinco a sete dias após as extrações, aparelhos ortodônticos fixos, prescrição MBT, slot de 0,022 " polegadas foram colados, em 
seguida arco de NiTi 0, 014" polegadas foi amarrilhado a cada braquete e imediatamente após a inserção do arco, uma dose do LBI, foi aplicado no grupo laser, comprimento de onda de $830 \mathrm{~nm}, 2,25 \mathrm{~J} / \mathrm{cm}^{2}$ de dose de irradiação. Cada raiz de canino a canino superior recebeu o feixe de laser, nas regiões cervical e apical, lado vestibular e palatino, desse modo cada dente recebeu 4 aplicações com tempo de exposição de 1 minuto/dente. Essa aplicação foi feita nos dias 3, 7 e 14 após a primeira e a cada 15 dias a partir do segundo mês, até que o nivelamento e alinhamento estivessem completos. Sequência de fios utilizados: 0, 014" NiTi, 0,016"x0,016" e 0,017"x0,025" NiTi e finalmente $0,019 \times 0,025$ aço. $O$ tratamento foi considerado concluído quando $\mathrm{o}$ nivelamento estava completo (figura 19). Para calcular as medidas, foram feitos modelos de estudo em quatro momentos: T0 (antes do primeiro arco), T1 (1 mês após o início), T2 (após 2 meses) e T3 (nivelamento e alinhamento). Foi encontrado uma diminuição de $26 \%$ no tempo global de tratamento no grupo controle. Apesar desse estudo conter limitações, foi o primeiro RCT de seu tipo, utilizando os melhores critérios, protocolo de laser e parâmetros para alcançar resultados e recomendações confiáveis e, com isso, conclui-se que a TLBI é um método eficaz para acelerar o movimento ortodôntico do dente em casos de apinhamentos dentários.

Figura 7: Progresso de dois casos no grupo laser e no grupo controle

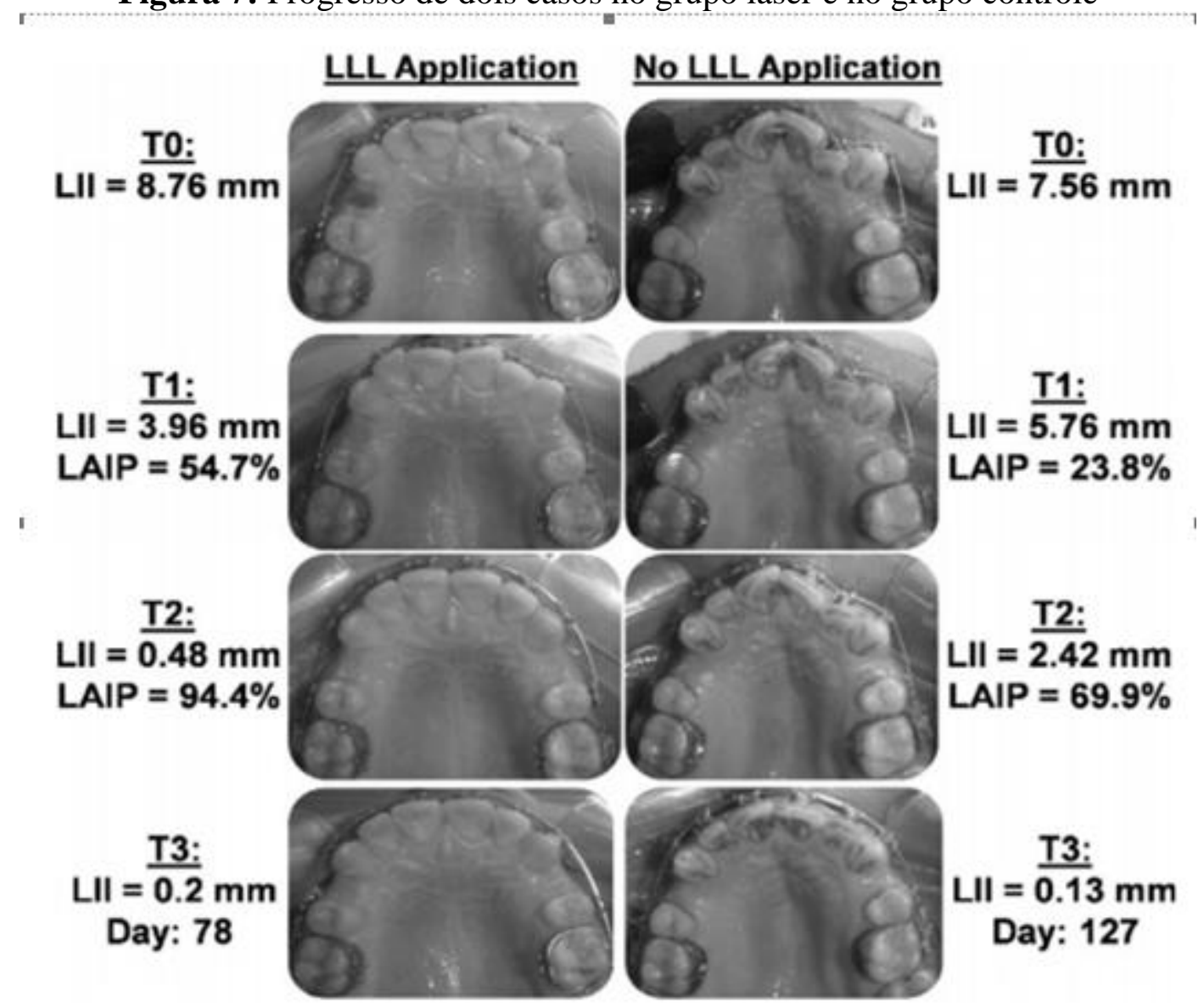

Fonte: Alsayed Hasan et al., 2017, p.501.

Qamruddin et al. (2017) realizaram o presente estudo com objetivo de avaliar os efeitos da terapia laser de baixa intensidade em intervalos de 3 semanas sobre a 
velocidade da movimentação dentária e a dor associada a ela em tratamentos ortodônticos com uso de braquetes autoligados MBT e slot 0,022. Foram selecionados 22 pacientes, sendo 11 homens e 11 mulheres, com idades entre 12 e 25 anos, com maloclusão Classe II Divisão I de Angle, que necessitavam extração bilateral de primeiros pré-molares na arcada superior. Foi usado uma sequência de fios 0,014", $0,016 ", 0,017$ ", 0,025 " e 0,019 "x 0,025 " por aproximadamente 6 meses, com troca de arco a cada 6 semanas e um fio final 0,019x0,025 de aço inoxidável. Vinte e um dias após a colocação do último fio, as extrações foram realizadas e uma moldagem de silicone foi obtida uma semana após as extrações. As retrações dos caninos foram iniciadas bilateralmente utilizando molas fechadas de NiTi de $6 \mathrm{~mm}$, com $150 \mathrm{~g}$ de força aplicada. Os incisivos foram conjugados com fio de amarrilho 0,010 para evitar diastemas. Cada hemiarcada superior foi dividida aleatoriamente em grupo experimental ou placebo. Terapia laser de baixa intensidade foi aplicada no grupo experimental, imediatamente, após aplicação da força de retração (T0), num total de 10 pontos, sendo 5 na vestibular e 5 na palatina. A irradiação foi realizada com laser de diodo de gálio e alumínio e arsênio, com comprimento de onda de $940 \mathrm{~nm}$ em modo contínuo e potência fixada em $100 \mathrm{~mW}$, com ponta de fibra ótica de $0,04 \mathrm{~cm}$ de diâmetro, por 3 segundos em cada um dos pontos, com a fibra óptica perpendicular e em leve contato direto com a mucosa. A densidade de energia em cada ponto foi de $7,5 \mathrm{~J}$ por $\mathrm{cm}^{2}$. O mesmo procedimento foi realizado no lado placebo, mas o aparelho estava desligado. Os pacientes foram chamados para proservação a cada 3 semanas por mais 3 visitas consecutivas (T1, T2 e T3). A terapia com laser foi realizada em T0, T1 e T2 e as impressões de silicone feitas em T0, T1, T2 e T3. Após cada aplicação de laser, o paciente recebeu um questionário sobre a dor, com uma escala de classificação numérica de 11 pontos, onde 0 indicava nenhuma dor e 10 dor intolerável. A dor deveria ser registrada 4 horas após o procedimento e, em seguida, a cada 24 horas por 7 dias sendo orientado a trazer o questionário preenchido na próxima consulta. Um scanner CAD/CAM foi usado para digitalizar os modelos obtidos e os movimentos dos caninos foram medidos digitalmente, permitindo a comparação de movimento dental do lado experimental com o lado placebo em T0, T1, T2 e T3. A duração total do estudo foi de 15 meses, sendo que, dos 22 pacientes iniciais da amostra, um homem e uma mulher foram excluídos do estudo, por quebra do aparelho e por uso de analgésico. A média de idade dos pacientes foi de 19,8 anos e não houve diferença na taxa de movimentação ortodôntica ou percepção de dor entre os sexos em T0, T1, T2 e T3. Foi encontrada diferença estatística significativa na taxa de retração de canino entre os grupos experimentais e placebo em T1, T2 e T3, sendo que o movimento no lado experimental foi 2,02 vezes maior que no lado placebo. A dor era significativamente menor no lado experimental no primeiro dia após aplicação de laser em T1 e T2 em comparação ao grupo placebo, ao passo que, no T3 e no restante dos dias em T1 e T2, não houve diferença estatística significante na percepção da dor entre os grupos. $O$ estudo concluiu que a aplicação de laser de baixa intensidade em intervalos de 3 semanas se encaixa bem no padrão de agendamento de consultas ortodônticas e pode duplicar a velocidade da movimentação ortodôntica e reduzir significativamente a dor associada.

Üretürk et al. (2017) realizaram este estudo para determinar os efeitos da terapia laser de baixa intensidade (TLBI) na quantidade de movimentação dentária, avaliação dos níveis de IL-1ß, TGF- $\beta 1$ no fluido do sulco gengival e possíveis alterações periodontais durante a distalização ortodôntica de caninos. O estudo contou com um 
total de 15 pacientes, sendo 8 mulheres e 7 homens, com idade média de 16,2 anos. Cada paciente teve um canino alocado no grupo controle (GC) e outro no grupo grupo submetido a TLBI (GL). Os primeiros pré-molares foram extraídos 2 semanas antes do início do nivelamento e alinhamento e, só após este, os caninos começaram a ser distalizados. Foram instalados braquetes metálicos Smart Clip com slot de 18 polegadas e bandas nos molares e, para distalizar os caninos, molas fechadas de NiTi foram instaladas entre o canino e o miniimplante, com forca de $150 \mathrm{~g}$ e ativadas nos dias 0,21 , 42, 63 e 84. A distalização foi avaliada num período total de 90 dias. Uma unidade laser diodo (GaAlAs) de baixa potência com comprimento de onda de $820 \mathrm{~nm}$, com saída de $20 \mathrm{~mW}$ em modo contínuo e energia de $5 \mathrm{~J} / \mathrm{cm}^{2}$ foi usada por 10 segundos em cada ponto de aplicação, resultando em $0,2 \mathrm{~J}$ de energia por ponto. Um total de 5 pontos vestibulares e 5 pontos palatinos foram irradiados em cada sessão. No lado controle, o aparelho laser foi posicionado nos mesmos 10 pontos mas o aparelho não foi acionado. A TLBI foi realizada nos dias $0,3,7,14,21,30,33,37,44,51,60,63,67,74,81,84$ e 90. Para avaliar a quantidade de movimentação as arcadas, foram escaneadas em 3D em quatro tempos distintos, na montagem do aparelho (T0), com 30 dias (T1), com 60 dias (T2) e com 90 dias (T3) (figura 20). Este estudo mostrou diferença estatística significativa de movimentação em T1 e T3, sendo no GL 40\% que no GC no T3 (Figura 21). Neste estudo, não foram evidentes alterações periodontais. Verificou-se aumento dos níveis de IL-1ß e TGF- $\beta 1$ no fluido do sulco gengival, mas mais estudos são necessários para elucidar os mecanismos exatos da influência da TLBI na atividade osteoblástica e osteoclástica. Os resultados sugerem que a aplicação de TLBI acelera significativamente o movimento dental em seres humanos mantendo os tecidos saudáveis.

Figura 08: Modelos escaneados para mensuração do movimento dentário
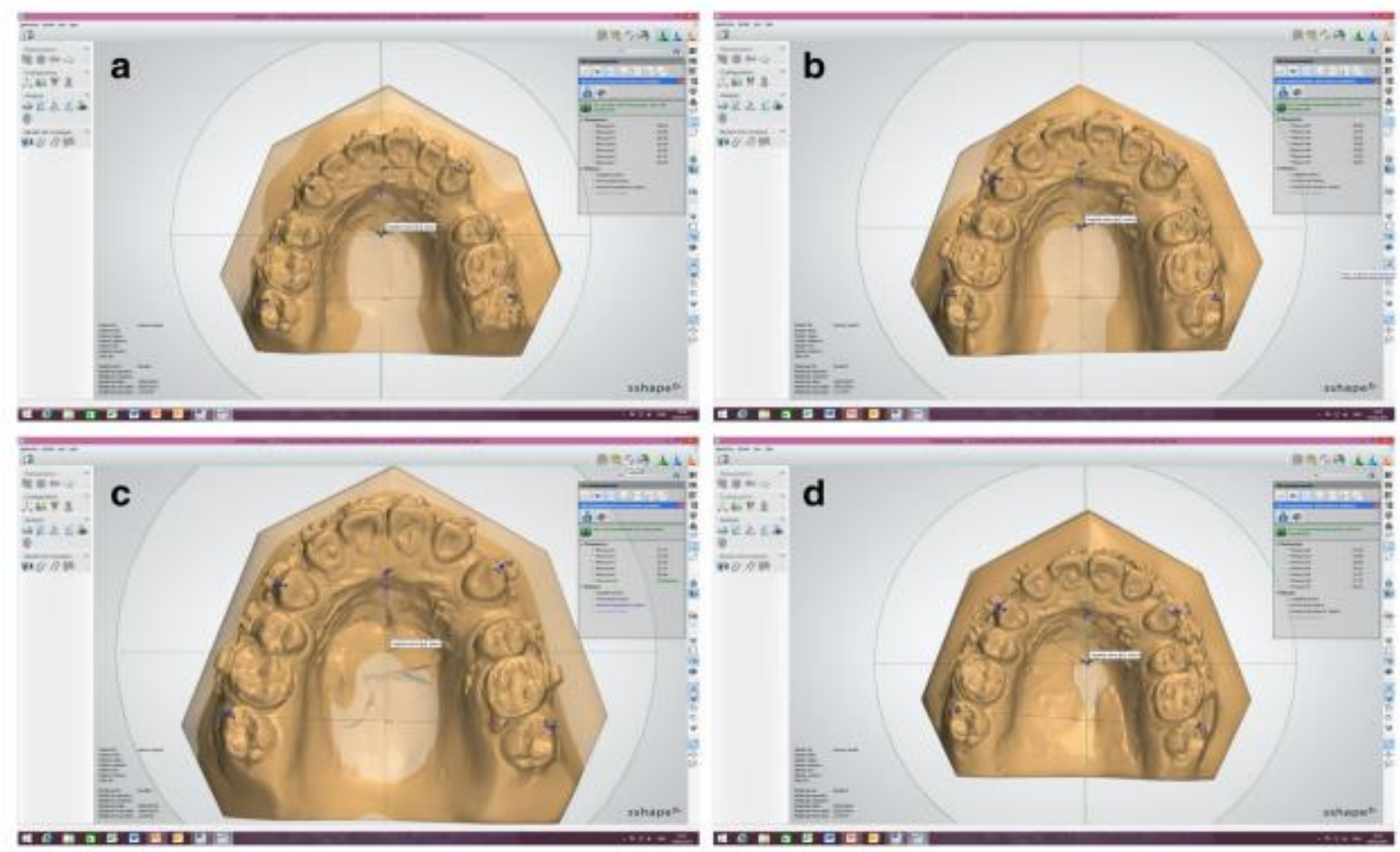

Fonte: Üretürk et al., 2017, p.760. 
Gráfico 02: Quantidade de movimento dentário em 90 dias

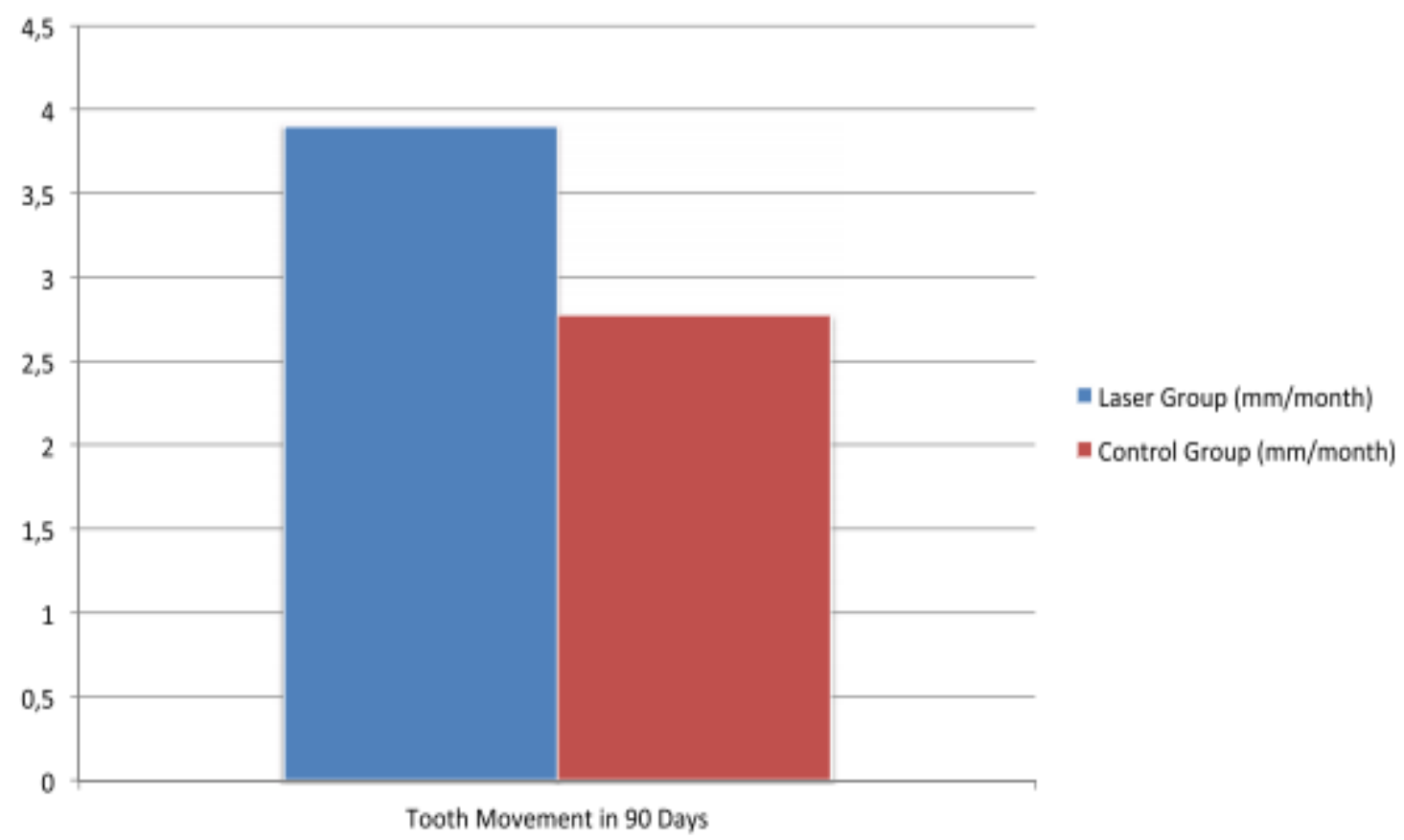

Fonte: Üretürk et al., 2017, p.761

Suzuki et al. 2018 realizaram este estudo com objetivo de comparar a taxa de movimentação dental, a quantidade de reabsorção radicular e as alterações ósseas alveolares em ratos. Um total de 60 hemimaxilas de 30 ratos foram divididas em 5 grupos: corticopunção (CP), terapia laser de baixa intensidade (TLBI), CP combinado com LBI $(\mathrm{CP}+\mathrm{LBI})$, controle $(\mathrm{C})$ e controle negativo $(\mathrm{CN})$. Para cada período experimental (14 e 21 dias), as hemimaxilas de 15 ratos $(n=30)$ foram avaliadas, sendo que 15 hemimaxilas do lado direito foram distribuídas aleatoriamente no grupo $\mathrm{C}$ $(\mathrm{n}=10)$ e no grupo $\mathrm{CN}(\mathrm{n}=5)$ e as outras 15 hemimaxilas do lado esquerdo foram tratadas e distribuídas nos grupos CP $(n=5)$, LBI $(n=5)$ e CP+LBI $(n=5)$. Para indução do movimento dental, um micro implante foi inserido a $1 \mathrm{~mm}$ da distal do incisivo superior e uma mola helicoidal de NiTi foi usada ligando o micro implante ao molar esquerdo e ao molar direito, criando uma força de $50 \mathrm{~g}$ nos molares na direção mesial (figura 22). Foi usada esta magnitude de força, pois estudos anteriores mostram que esta força é capaz de promover movimentação dental e reabsorção radicular em ratos. A irradiação foi realizada usando um laser diodo (GaAlAs), comprimento de onda de $810 \mathrm{~nm}$, energia de saída de $100 \mathrm{~mW}$. Foram usados como parâmetros: irradiação pontual por 15 segundos na região vestibular e palatina, nos dias $0,2,4,6,8,10$ e 12 . A energia por ponto foi de $1,5 \mathrm{~J}$, resultando em uma fluência de $75 \mathrm{~J} / \mathrm{cm}^{2}$ de cada lado. A outra hemimaxila não foi irradiada e recebeu uma barreira de metal para evitar irradiação indireta. A corticopunção foi realizada em 3 pontos, 2 com $0,7 \mathrm{~mm}$ de profundidade no osso palatino e um com $5 \mathrm{~mm}$ de profundidade mesial ao primeiro molar. O movimento 
dos dentes foi avaliado medindo o espaço entre os molares e o centro do micro implante e subtraindo a distância medida no dia 0 e no dia 14 ou 21 . O osso alveolar e as raízes dos molares de todas as hemimaxilas foram avaliadas em microtomografias de varredura, pesquisando densidade e volume ósseo, espessura trabecular e o volume das reabsorções radiculares. Foi realizada análise histológica das raízes e ossos, fazendo uma análise descritiva da qualidade óssea e das reabsorções radiculares, além da contagem do número de osteoclastos na áreas de tensão e compressão provocadas pela movimentação ortodôntica. Nos dias 14 e 21, o movimento do dente foi significativamente maior nos grupos $\mathrm{CP}+\mathrm{LBI}$ em comparação com os grupos CP e LBI. Os 3 grupos teste $\mathrm{CP}$, LBI, $\mathrm{CP}+\mathrm{LBI}$ apresentaram movimento significativamente maior dos dentes em comparação ao $\mathrm{C}$ (controle). Embora no dia 21 o $\mathrm{CP}$ tenha mostrado mais deslocamento dental que o LBI, não houve diferença estatisticamente significativa entre os grupos. Este estudo mostra que LBI e CP podem acelerar, independentemente, o movimento do dente e reduzir a reabsorção radicular externa, melhorando o processo de remodelação óssea. A CP parece ter mais impacto na atividade catabólica no lado de compressão e o laser na atividade anabólica no lado de tensão.

Figura 09: Acessórios ortodônticos utilizados para movimentação dentária

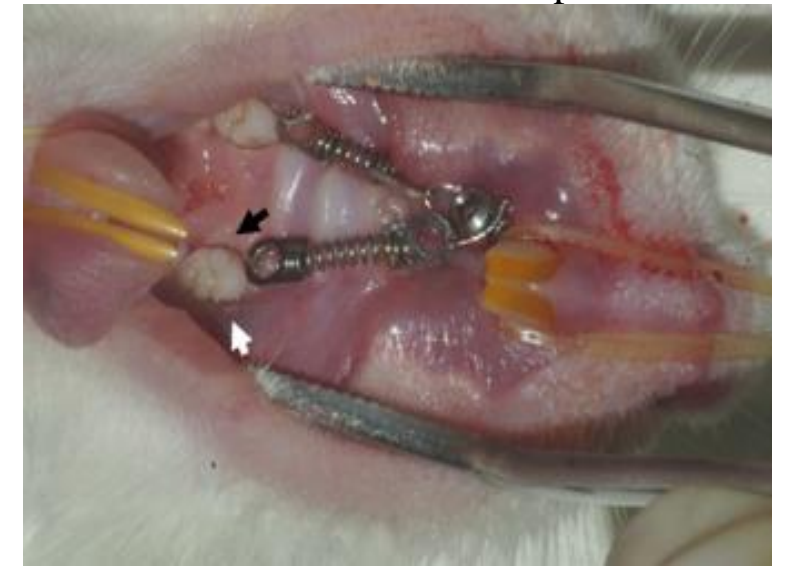

Fonte: Suzuki et al., 2018, p.813

Guram et al. (2018) realizaram este estudo randomizado controlado duplo cego com objetivo de avaliar o papel da terapia laser de baixa potência (TLBP) na duração da movimentação ortodôntica (MO) e percepção da dor durante a MO. Foram avaliados 20 pacientes classe I de Angle, sendo 12 do gênero feminino e 8 do gênero masculino, com idades entre 17 e 24 anos, entre abril de 2013 e julho de 2016. Os pacientes tiveram os primeiros pré-molares superiores e inferiores extraídos em ambos os lados, 3 meses antes de iniciar o movimento de retração dos caninos. Cada quadrante da mandíbula e da maxila de cada paciente foi alocado aleatoriamente em grupo controle (GC) e grupo laser (GL). O tratamento ortodôntico inicial inclui alinhamento e nivelamento de caninos, segundos pré-molares e primeiro molares. Foi usado sistema (prescrição) MBT, com slot de 0,022". Os caninos foram retraídos utilizando alças de fecho seccional, de fios de aço 16x22 com 5 e $7 \mathrm{~mm}$ de comprimento na mandíbula e maxila, respectivamente, com força de $150 \mathrm{~g}$. As alças foram reativadas a cada mês para $2 \mathrm{~mm}$. A quantidade de movimentação dental foi determinada através da medição da distância entre a cúspide do canino e a ponta de cúspide mesiovestibular do primeiro molar em modelos de gesso após aplicação de força, utilizando compasso digital. O GL foi 
irradiado com TLBP GaAlAs $\left(810 \mathrm{~nm}, 5 \mathrm{~J} / \mathrm{cm}^{2}\right)$, potência de $0,2 \mathrm{~W}$ e uma frequência de $2 \mathrm{~Hz}$. As aplicações se deram por vestibular e lingual/palatina, por $80 \mathrm{~s}$, semanalmente por 21 dias. A quantidade de retração foi avaliada em 4 pares de moldes para cada paciente no início da retração $(\mathrm{C} 1), 2$ meses após a retração $(\mathrm{C} 2), 3$ meses após a retração (C3) e depois de concluída a movimentação (C4). A taxa de retração foi avaliada em T1 aos 2 meses, T2 aos 4 meses (C3-C1), e T3 no término (C4-C1). Os pacientes foram orientados a gravar o nível de dor experimentado nos dias 1 a 7 após a aplicação do laser na escala Wong-Baker Faces Rating Scale". Ao avaliar as taxas de retração do canino, o estudo relata não haver diferença estatisticamente significante quanto à idade e ao gênero dos participantes. Há diminuição estatisticamente relevante na taxa de retração no GL em comparação ao GC e, no GL, a taxa de retração é estatisticamente maior na maxila do que na mandíbula e, no GC, não existe diferença estatística nas taxas de retração entre GC e GL. Com relação a dor referida pelos pacientes, houve diminuição estatisticamente significativa até o segundo dia no GL em comparação ao GC, sendo que, após o dia 3, não houve diferença estatística. O presente estudo conclui que TLBP pode reduzir o tempo e a experiência de dor durante a MO.

\section{DISCUSSÃO}

$\mathrm{Na}$ ortodontia, a laserterapia tem se mostrado eficiente no controle da analgesia e biomodulação tecidual. A terapia a laser na aceleração da movimentação ortodôntica atua na capacidade de interferir no metabolismo celular, acelerando o processo de reabsorção e neoformação óssea e vem sendo utilizada pelos benefícios que ela pode promover como diminuição da dor, do tempo de tratamento e do custo por parte do paciente. $\mathrm{O}$ tratamento mais prolongado pode implicar em maiores chances de perda óssea alveolar, reabsorção radicular e alterações gengivais além de maior probabilidade de cárie.

Algumas revisões sistemáticas (LONG et al., 2013; ALMPANI e KANTARCI, 2016; MILES, 2017) comparam as diversas técnicas para promover aceleração da movimentação ortodôntica demostrando evidências científicas de vantagens e desvantagens de cada uma. Inúmeros métodos são utilizados, desde os mais invasivos como a micro osteoperfuração, piezocisão, corticotomia e osteotomias, até os menos invasivos como o uso de medicações corticosteróides, vitamina D3, hormônio da paratireióide, tiroxina e prostaglandinas, microvibração, campos eletromagnéticos, correntes elétricas, terapia de luz (LED) e o laser de baixa intensidade. Para Long et al. (2013) e Miles (2017), só é seguro afirmar que a corticotomia acelera a movimentação ortodôntica e o laser, apesar de benéfico e seguro, não promove aceleração do movimento; em contrapartida, Almpani e Kantarci (2016) afirmam que existe aceleração e ausência de dor, tornando-se atrativa aos pacientes; Qamruddin et al. (2015), por sua ves, encontraram resultados semelhantes em animais, no entanto, mais estudos devem ser feitos para criar um protocolo na prática clínica.

Alguns experimentos como os de Suzuki et al. (2016), Gonçalves et al. (2016), Milligan et al. (2017) e Suzuki et al. (2018) foram feitos em ratos, já Seifi et al. (2007) realizaram em coelhos, outros os realizaram em humanos para confirmar a eficiência do laser na aceleração do movimento (URETURK et al., 2017; ALSAYED HANSAN et $a l, 2017$; DOSHI-MEHTA e BHAD-PATIL, 2012; CRUZ et al, 2004) . 
O desafio de qualquer técnica promissora é avaliar além de sua eficácia, os efeitos locais e sistêmicos. Suzuki et al. (2018) compararam corticopunção e laser de baixa intensidade e avaliaram histologicamente as consequências da remodelação óssea com 14 e 21 dias de movimentação, já Gonçalves et al. (2016) compararam 7 e 14 dias.

Os resultados obtidos com a terapia a laser no número de células osteoclásticas e osteoblásticas envolvidas na movimentação ortodôntica são positivos em ambos os estudos. Embora tenham usado o mesmo tipo de irradiação a laser (GaAlAs), o comprimento de onda, potência e tempo de exposição foram diferentes.

A grande maioria dos autores (GURAM et al., 2018; URETÜRK et al., 2017; SOUSA et al., 2011; DALAIE et al., 2015; CRUZ et al., 2004) são unânimes no tipo de laser de baixo nível diodo usado, um semicondutor GaAlAs (Arseneto de GálioAlumínio) emissor de radiação infravermelha no comprimento de onda variando entre 780-880nm; porém, outras pesquisas utilizaram outros aparelhos que emitem comprimento de onda inferiores de 630nm a 670nm (DOMINGUEZ et al., 2015) e superiores a 850nm (NAHAS et al., 2017; LIMPANICHKUL et al., 2006) e (CHUNG et al., 2015) usou dispositivo de LED (diodo emissor de luz) para realizar a fotobiomodulação, mas seus resultados foram negativos na taxa de movimentação ortodôntica. Seifi et al. (2007) fizeram um estudo em coelhos comparando a terapia com comprimentos de onda $850 \mathrm{~nm}$ e $630 \mathrm{~nm}$ e não encontraram resultados diferentes; no entanto, melhores no grupo laser do que o grupo controle.

A maioria dos estudos envolvem a mecânica de retração de caninos e a medição da taxa de movimentação com o objetivo de reduzir o tempo de tratamento com exceção de Nahas et al. (2017) e Alsayed Hasan et al. (2017) que averiguaram a eficácia do laser no apinhamento dentário, sendo muito satisfatório. A faixa etária envolvida nas pesquisas variou de 12 a 25 anos e adultos jovens foi a eleição (GURAM et al., 2018; LIMPANICHKUL et al., 2006; QAMRUDDIN et al., 2017; DOSHI-MEHTA e BHAD-PATIL, 2012) por se tratar de um perfil com mais interesse no tratamento ortodôntico acelerado. Comumente, as retrações dos caninos são feitas por mecânica de fricção deslizante ou atrito não-mecânico (FARSAIL E AL-JEWAIR, 2017); em nossa revisão, grande parte das técnicas de retração foi por meio de molas fechadas de NiTi utilizando uma força de $150 \mathrm{~g}$, medidas com tensiômetro, pois consiste de uma técnica contínua quando comparada com elásticos.

A literatura médica não padroniza a região anatômica para a aplicação do laser; no entanto, os estudos foram feitos na região vestibular e palatina do dente a ser retraído (ALMEIDA et al, 2016). As aplicações foram divididas em terço médio, cervical e apical da raiz, podendo variar de 4 aplicações (ALSAYED HANSAN et al., 2017) que excluiu o terço médio, 8 aplicações (DALAIE et al., 2015; GURAM et al., 2018) e 10 aplicações ( SOUSA et al., 2011; GENC et al., 2013; URETURK et al., 2017; DOSHIMEHTA e BHAD-PATIL, 2012; QAMRUDDIN et al., 2017) no total/dente. Muitos estudos (CRUZ et al., 2004; DOSHI-MEHTA e BHAD-PATIL, 2012; GENC et al., 2013; SOUSA et al., 2011; YOUSSEF et al., 2008) revelam que a aplicação de laser, mais de uma vez por mês, é necessária para promover aceleração; porém, o ideal seria ter apenas uma aplicação somente quando fosse haver a ativação do aparelho ortodôntico fixo, diminuindo o número de visitas do paciente ao consultório odontológico como relatam Qamruddin et al. (2017) fazendo a aplicação a cada 3 semanas.

A taxa de movimentação ortodôntica foi avaliada e mensurada, geralmente, num intervalo de 1, 2 e 3 meses (LONG et al., 2015). A medição, na maior parte das vezes, 
foi medida dos caninos aos primeiros molares, sendo a ancoragem posterior muito importante para a precisão dos resultados (DOSHI-MEHTA e BHAD-PATIL, 2012; CRUZ et al., 2004). A aceleração na taxa de movimentação na retração dos caninos foi aumentada, variando de 1,3 vezes mais com Doshi-Mehta e Bhad-Patil (2012), em torno 2,02 vezes mais com Sousa et al. (2011), Youssef et al. (2008) e Qamruddin et al. (2017). Ge et al. (2015) também relataram um aumento; porém, no movimento dos incisivos laterais. Ureturk et al. (2017) encontraram resultados $40 \%$ mais rápidos no grupo laser frente ao grupo controle.

Sousa et al. (2011) e Cruz et al. (2004) utilizaram protocolos parecidos variando de 6 a 8J /mês de dose de irradiação, 780nm de comprimento de onda, 10s de tempo de exposição e, estaticamente aumentando a velocidade, sendo uma informação relevante para determinar uma dose de laser ideal e necessária para obter movimento ortodôntico mais rápido e menos tempo de cadeira. Estes resultados não estão de acordo com Limpanichkul et al. (2006); porém, eles usaram uma dose muito maior por dente $(18,4 \mathrm{~J})$. Baseado nestas informações em estudos futuros, o uso de 1 ou 2 aplicações de LBP mensais podem ser suficientes para alcançar os mesmos resultados, em relação a movimentação dentária. (QAMRUDDIN et al., 2017).

A evidência apresentada pelas revisões sistemáticas (FARSAIL E AL-JEWAIR, 2017) e estudos recentes favorecem o uso do LBI em acelerar as retrações de caninos e a modulação da dor. Doshi-Mehta e Bhad-Patil (2012), Youssef et al. (2008) e Qamruddin et al. (2017) consideraram eficaz o laser para reduzir os níveis de dor; entretanto, Limpanichkul et al. (2006) não encontraram nenhuma diferença significante. Os efeitos colaterais do tratamento com LBI devem ser considerados antes do seu uso na prática clínica (SONESSON et al., 2016). O movimento acelerado aumenta o risco de reabsorção radicular; mas, apenas dois estudos utilizaram radiografias para monitorar essas possíveis alterações radiográficas (DOSHI-MEHTA e BHAD-PATIL, 2012; SOUSA et al., 2011). Suzuki et al. (2016) também avaliaram por cortes histológicos em ratos e ambos demonstraram não ocorrer a reabsorção radicular; portanto, a associação de movimentação ortodôntica juntamente com o uso de LBI torna-se, por muitas vezes, efetiva (SUZUKI et al., 2018).

\section{CONCLUSÃO}

A revisão de literatura mostrou:

- Resultados clínicos satisfatórios com o LBI na aceleração do movimento ortodôntico;

- Ser uma boa opção técnica não invasiva e eficaz quando comparado a procedimentos cirúrgicos pouco invasivos, como a corticocisão, a microosteoperfuração e a corticopunção.

- O laser aumenta a taxa de movimento do dente de forma fisiológica, estimulando reabsorção e neoformação óssea, sem causar efeitos colaterais no periodonto, diminuindo a área e o volume de reabsorção radicular e a dor.

- A heterogeneidade dos resultados encontrados pode ser explicada pela ausência de um protocolo clínico de irradiação de laser, apesar da maioria dos trabalhos apresentarem resultados positivos no aumento da movimentação dentária. 


\section{REFERÊNCIAS BIBLIOGRÁFICAS}

ALMPANI, K.; KANTARCI A. Nonsurgical Methods for the Acceleration of the Orthodontic Tooth Movement. Front Oral Biol, v.18, p.80-91, 2016.

ALSAYED HASAN, M.M.A.; SULTAN, K.; HAMADAD, O. Low-level laser therapy effectiveness in accelerating orthodontic tooth movement: A randomized controlled clinical trial. Angle Orthod, v. 87, n.4, p. 499-504, Julho, 2017.

CHUNG, S.E.; TOMPSON, B.; GONG, S.G. The effect of light emitting diode phototherapy on rate of orthodontic tooth movement: a split mouth, controlled clinical trial. J Orthod, v. 42, n. 4, p. 274-83, 2015.

CRUZ, D.R.; KOHARA, E.K.; RIBEIRO, M.S.; WETTER, N.U. Effects of LowIntensity Laser Therapy on the Orthodontic Movement Velocity of Human Teeth: A Preliminary Study. Lasers Surg Med, v. 35, n. 2, p. 117-20, 2004.

DALAIE, K.; HAMEDI, R.; KHARAZIFARD, M.J.; MAHDIAN M.; BAYAT, M. Effect of low-level laser therapy on orthodontic tooth movement: a clinical investigation. J Dent (Tehran), v.12, n.4, p. 249-256, abril, 2015.

DE ALMEIDA, V.L.; DE ANDRADE GOIS, V.L.; ANDRADE, R.N.; CESAR, C.P.; DE ALBUQUERQUE-JUNIOR, R.L.; DE MELLO RODE, S.; PARANHOS, L.R. Efficiency of low-level laser therapy within induced dental movement: A systematic review and meta-analysis. J Photochem Photobiol B, v.158, p. 258-66, maio, 2016.

DOMÍNGUEZ, A.; GÓMEZ, C.; PALMA, J.C. Effects of low-level laser therapy on orthodontics rate of tooth movement, pain, and release of RANKL and OPG in GCF. Lasers Med Sci, v. 30, n. 2, p. 915-23, fevereiro, 2015.

DOSHI-MEHTA, G.; BHAD-PATIL, W.A.; Efficacy of low intensity laser therapy in reducing treatment time and orthodontic pain: a clinical investigation. Am J Orthod Dentofacial Orthop, v. 141, n. 3, p. 289-97, março, 2012.

EKIZER, A.; TÜRKER, G.; UYSAL, T.; GÜRAY, E.; TASDEMIR, Z. Light Emitting Diode Mediated Photobiomodulation Therapy Improves Orthodontic Tooth Movement and Miniscrew Stability: A Randomized Controlled Clinical Trial. Lasers Surg Med; v. 48, n.10, p. 936-943, dezembro, 2016.

FARSAIL, A.; AL-JEWAIR, T. Insufficient Evidence Supports the Use of Low-Level Laser Therapy to Accelerate Tooth Movement, Prevent Orthodontic Relapse, and Modulate Acute Pain During Orthodontic Treatment. J Evid Based Dent Pract, v.17, n.3, p. 262-264, setembro, 2017.

GE, M.K.; HE, W.L.; CHEN, J.; WEN, C.; YIN, X.; HU, Z.A.; LIU, Z.P.; ZOU, S.J. Efficacy of low-level laser therapy for accelerating sispitooth movement during orthodontic treatment: a systematic review and meta-analysis. Lasers Med Sci, v.30, n.5, p. 1609-18, julho, 2015. 
GENC, G.; KOCADERELI, I.; TASAR, F.; KILINC, K.; EL, S.; SARKARATI, B. Effect of low-level laser therapy (LLLT) on orthodontic tooth movement. Lasers Med Sci, v. 28, n. 1, p. 41-7, janeiro, 2013.

GONÇALVES, C.F.; DESIDERÁ, A.C.; DO NASCIMENTO, G.C.; ISSA, J.P.; LEITEPANISSI,C.R. Experimental tooth movement and photobiomodulation on bone remodeling in rats. Lasers Med Sci, v. 31, n. 9, p. 1883-1890, dezembro, 2016.

GURAM, G.; REDDY, R.K.; DHARAMSI, A.M.; SYED ISMAIL, P.M.; MISHRA, S.; PRAKASHKUMAR, M.D. Evaluation of Low-Level Laser Therapy on Orthodontic Tooth Movement: A Randomized Control Study. Contemp Clin Dent, v. 9, n. 1, p. 105-109, janeiro-março, 2018.

LIMPANICHKUL, W.; GODFREY, K.; SRISUK, N.; RATTANAYATIKUL, C. Effects of low-level laser therapy on the rate of orthodontic tooth movement. Orthod Craniofac Res, v. 9, n.1, p. 38-43, fevereiro, 2006.

LONG, H.; PYAKUREL, U.; WANG, Y.; LIAO, L.; ZHOU, Y; LAI, W. Interventions for accelerating orthodontic tooth movement: a systematic review. Angle Orthod, v. 83, n. 1, p. 164-71, janeiro, 2013.

LONG, H.; ZHOU, Y.; XUE, J.; LIAO, L.; YE, N.; JIAN, F.; WANG, Y.; LAI, W. The effectiveness of low level laser therapy in accelerating orthodontic tooth movement: a meta-analysis. Lasers Med Sci, v. 30, n. 3, p. 1161-70, abril, 2015.

MILLIGAN, M.; ARUTCHELVAN, Y.; GONG, S.G. Effects of two wattages of lowlevel laser therapy on orthodontic tooth movement. Arch Oral Biol, v. 80, p. 62-68, agosto, 2017.

NAHAS, A.Z.; SAMARA, S.A.; RASTEGAR-LARI, T.A. Decrowding of lower anterior segment with and without photobiomodulation: a single center, randomized clinical trial. Lasers Med Sci, v.32, n. 1, p. 129-135, janeiro, 2017.

MILES, P. Accelerated Orthodontic treatment-What's the evidence? Aust Dent J, v. 62, Suppl 1, p. 63-70, março, 2017.

QAMRUDDIN, I.; ALAM, M.K.; KHAMIS, M.F.; HUSEIN, A. Minimally Invasive Techniques to Accelerate the Orthodontic Tooth Movement: A Systematic Review of Animal Studies. Biomed Res Int, 608530, 2015.

QAMRUDDIN, I.; ALAM, M.K.; MAHROOF, V.; FIDA, M.; KHAMIS, M.F.; HUSEIN, A. Effects of low-level laser irradiation on the rate of orthodontic tooth movement and associated pain with self-ligating brackets. Am J Orthod Dentofacial Orthop, v. 152, n. 5, p. 622-630, novembro, 2017. 
SEIFI, M.; SAFEEI, H.A.; DANESHDOOST, S.; MIR, M. Effects of two types of lowlevel laser wave lengths $(850$ and $630 \mathrm{~nm})$ on the orthodontic tooth movements in rabbits. Lasers Med Sci, v. 22, n. 4, p. 261-4, novembro, 2007.

SEIFI, M.; VAHID-DASTJERDI, E. Tooth movement alterations by different low level laser protocols: a literature review. J Lasers Med Sci, v.6, n.1, p.1-5, inverno, 2015.

SONESSON, M.; DE GEER, E.; SUBRAIAN, J.; PETRÉN, S. Efficacy of low-level laser therapy in accelerating tooth movement, preventing relapse and managing acute pain during orthodontic treatment in humans: a systematic review . BMC Oral Health, v.7, n. 17, p. 1-11, julho, 2016.

SOUSA, M.V.; SCANAVINI, M.A.; SANNOMIYA, E.K.; VELASCO, L.G.; ANGELIERI, F. Influence of low-level laser on the speed of orthodontic movement. Photomed Laser Surg, v. 29, n. 3, p. 191-6, março, 2011.

SUZUKI, S.S.; GARCEZ, A.S.; SUZUKI, H.; ERVOLINO, E.; MOON, W.; RIBEIRO, M.S.Low level laser therapy stimulates bone metabolism and inhibits root resorption during tooth movement in a rodent model. J Biophotonics, v. 9, n. 11-12, p. 1222-1235, dezembro, 2016.

SUZUKI, S.S.; GARCEZ, A.S.; REESE, P.O.; SUZUKI, H.; RIBEIRO, M.S.; MOON, W. Effects of corticopuncture (CP) and low-level laser therapy (LLLT) on the rate of tooth movement and root resorption in rats using micro-CT evaluation. Lasers Med Sci, v. 33, n. 4, p. 811-821, maio, 2018.

ÜRETÜRK, S.E.; SARAÇ, M.; FIRATH, S.; CAN, Ş.B.; GÜVEN, Y.; FIRATH, E. The effect of low-level laser therapy on tooth movement during canine distalization. Lasers Med Sci, v. 32, n. 4, p. 757-764, maio, 2017.

YOUSSEF， M.; ASHKAR， S.; HAMADE， E.; GUTKNECHT， N.; LAMPERT, F.; MIR, M. The effect of low-level laser therapy during orthodontic movement: a preliminary study. Lasers Med Sci, v. 23, n. 1, p. 27-33, janeiro, 2008. 